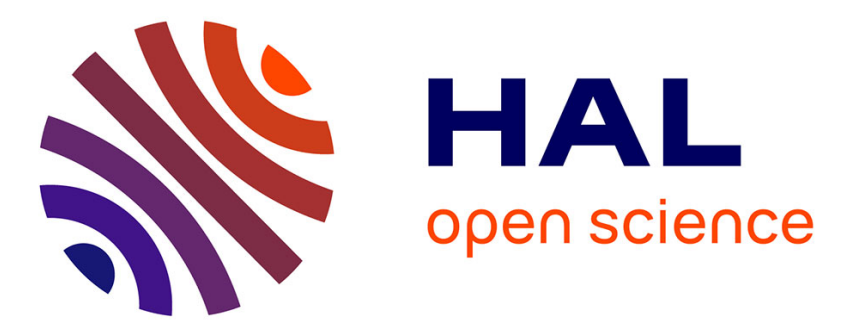

\title{
Dynamic recrystallization by subgrain rotation in olivine revealed by electron backscatter diffraction
}

Marco A Lopez-Sanchez, Andrea Tommasi, Walid Ben Ismail, Fabrice Barou

\section{To cite this version:}

Marco A Lopez-Sanchez, Andrea Tommasi, Walid Ben Ismail, Fabrice Barou. Dynamic recrystallization by subgrain rotation in olivine revealed by electron backscatter diffraction. Tectonophysics, 2021, pp.228916. 10.1016/j.tecto.2021.228916 . hal-03312394

\section{HAL Id: hal-03312394 \\ https://hal.science/hal-03312394}

Submitted on 2 Aug 2021

HAL is a multi-disciplinary open access archive for the deposit and dissemination of scientific research documents, whether they are published or not. The documents may come from teaching and research institutions in France or abroad, or from public or private research centers.
L'archive ouverte pluridisciplinaire HAL, est destinée au dépôt et à la diffusion de documents scientifiques de niveau recherche, publiés ou non, émanant des établissements d'enseignement et de recherche français ou étrangers, des laboratoires publics ou privés. 
Author copy of the article accepted for publication in Tectonophysics.

Please cite as: Lopez-Sanchez M.A., Tommasi, A., Ben Ismail, W., Barou. F. Dynamic recrystallization by subgrain rotation in olivine revealed by electron backscatter diffraction. Tectonophysics, doi: 10.1016/j.tecto.2021.228916

\title{
Dynamic recrystallization by subgrain rotation in olivine revealed by electron backscatter diffraction
}

\author{
Marco A. Lopez-Sanchez ${ }^{\text {a, }}$, Andrea Tommasi ${ }^{a}$, Walid Ben Ismail ${ }^{\text {b,c }}$, Fabrice Barou ${ }^{\text {a }}$

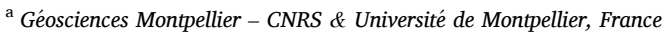 \\ ${ }^{\mathrm{b}}$ Rock Deformation Laboratory, Dept. Earth Sciences, University of Manchester, UK \\ ${ }^{\mathrm{c}}$ Now at K\&M Technology Group, Houston, United States
}

\section{Keywords:}

Olivine

Dynamic recrystallization

Subgrain rotation recrystallization

Geometrically necessary dislocations

Electron backscatter diffraction

Crystal preferred orientation

Misorientation

\begin{abstract}
A B S T R A C T
We document how dynamic recrystallization by subgrain rotation (SGR) develops in natural olivine-rich rocks deformed in extension to up to $50 \%$ bulk finite strain (1473 K, confining pressure of $300 \mathrm{MPa}$, and stresses between 115 and $180 \mathrm{MPa}$ ) using electron backscatter diffraction (EBSD) mapping. SGR occurs preferentially in highly deformed grains (well-oriented to deform by dislocation glide) subjected to local stress concentrations due to interactions with hard neighboring grains (poorly-oriented olivine crystals or pyroxenes). Subgrains (misorientation $<15^{\circ}$ ) are mainly delimited by tilt walls composed of combinations of dislocations of the [100] (001), [001](100), [100](010) and [001](010) systems, in order of decreasing frequency. The activation and prevalence of these systems agree with a Schmid factor analysis using data for high- $T$ dislocation creep in olivine. The development of closed 3D subgrain cells by SGR recrystallization requires the contribution of at least three different slip systems, implying the activation of hard slip systems and high (local) stresses. The transition from subgrain to grain boundaries (misorientation $\geq 15^{\circ}$ ) is characterized by a sharp change in the misorientation axes that accommodate the difference in orientation between the two subgrains or grains. We propose that this change marks the creation and incorporation of new defects (grain boundary dislocations with different Burger vectors and, likely, disclinations or disconnections) at the newly-formed grain boundaries and that this might be favoured by stress concentrations due to increasing misalignment between slip systems across the boundary. Finally, we document the development of strong misorientations within the parent grains, due to the accumulation of low angle grain boundaries, and between them and the recrystallized grains. SGR recrystallization may thus produce strong dispersion of the crystal preferred orientation without the need for grain boundary sliding.
\end{abstract}

\section{Introduction}

When large ductile (viscoplastic) strain occurs in the lithosphere, all major rock-forming minerals undergo dynamic recrystallization (DRX). DRX modifies the microstructure (grains size, shape, and arrangement) and the crystal preferred orientation (CPO) and decreases the dislocation content of the rock. By consequence, DRX modifies the strength and changes the anisotropy of the physical properties of rocks. These changes can potentially enable or disable strain localization by varying the strength distribution within a rock volume. Understanding how dynamic recrystallization evolves at the microscale is thus key for determining how rocks respond to deformation up to lithospheric scales. This knowledge is essential for mineral phases like olivine, which makes up most of the lithosphere and the upper convective mantle.
DRX involves the creation or migration of grain boundaries during plastic deformation to form new grains with a lower dislocation content than the host material (Doherty et al., 1997; Urai et al., 1986). Two main DRX mechanism exist, grain boundary migration (GBM) and subgrain rotation (SGR) recrystallization (Guillope and Poirier, 1979; Sakai et al., 2014; Urai et al., 1986), which are referred to as discontinuous and continuous dynamic recrystallization, respectively, in materials science (Huang and Logé, 2016). GBM proceeds by nucleation and growth by grain boundary migration of new grains while SGR generates new grains by progressive rotation of subgrains cells (coherent volumes within a crystal delimited by subgrain walls) with limited grain boundary migration (Drury and Pennock, 2007; Ion et al., 1982; Poirier and Guillope, 1979; Poirier and Nicolas, 1975). Depending on the deformation conditions, mainly temperature and strain rate, both

\footnotetext{
* Corresponding author.

E-mail address: marco-antonio.lopez-sanchez@umontpellier.fr (M.A. Lopez-Sanchez).
} 


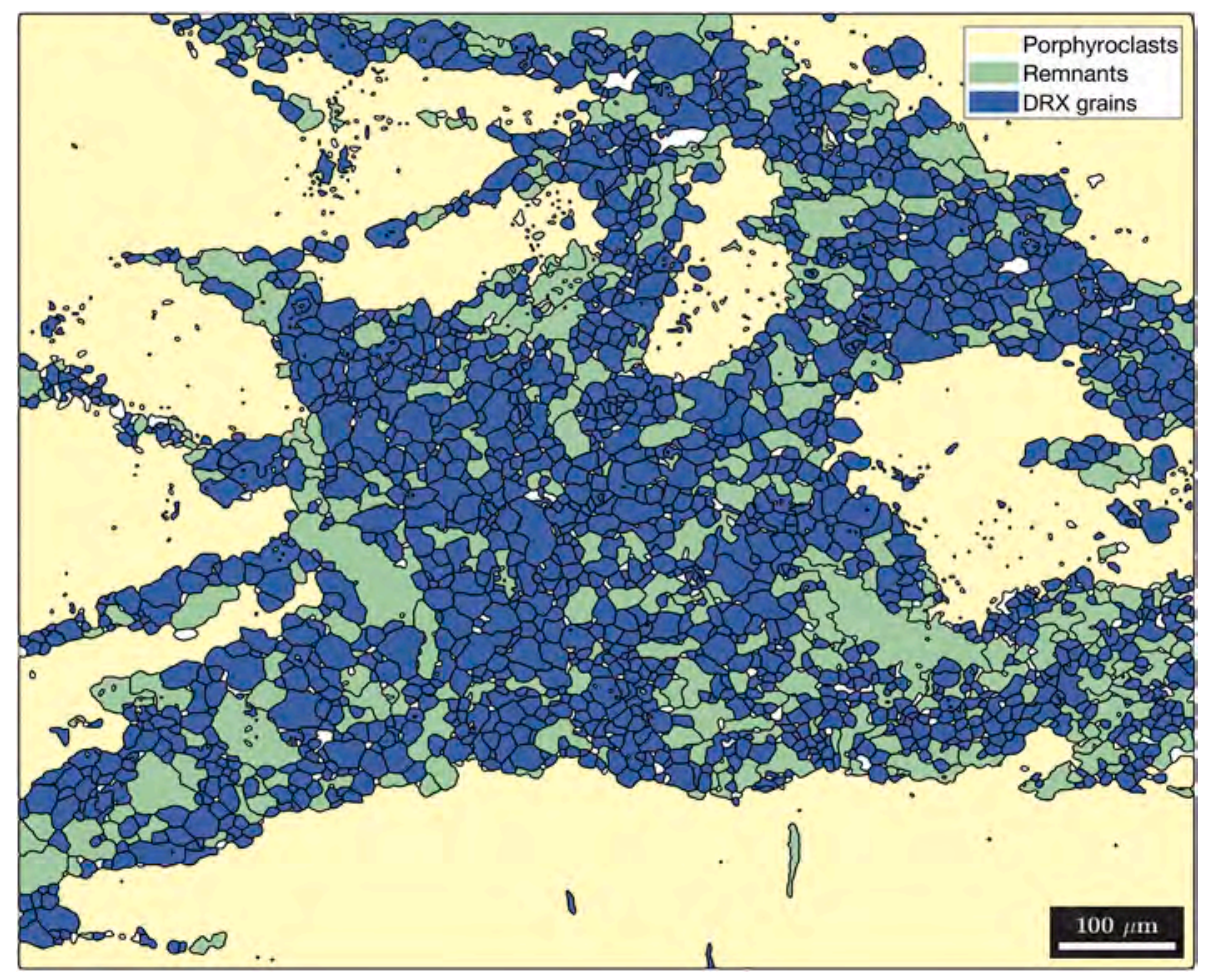

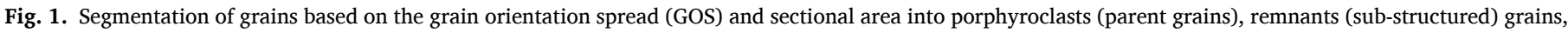
and dynamically recrystallized grains. Sample VS15ab1.

mechanisms may operate alone, in parallel with one dominating the other, or in a cooperative manner. Here we focus on SGR, a ubiquitous DRX mechanism in rock-forming minerals.

SGR recrystallization involves the formation of new grain boundaries within a grain by the progressive organization of dislocations, via glide, climb, and cross-slip, into planar (2D) arrays. These dislocation planar arrays are called low angle boundaries (LAB) or subgrain walls. They produce sharp (on a micrometric scale) changes in the lattice orientation, which are a function of the nature and density of dislocations within the array. Tilt walls are dominantly composed of edge dislocations, whereas twist walls are dominantly composed of screw dislocations. These two end-member types of LAB differ by the orientation of the rotation axis that accommodates the mismatch between the crystal lattice across them relative to the boundary plane: parallel to the boundary in a tilt wall and normal to it in a twist wall. The misorientation angle (the angle needed to put the crystal lattice on the two sides of the boundary in coincidence) is proportional to the density of dislocations in the LAB. During SGR recrystallization, the misorientation angle increases progressively by incorporation of dislocations within it, to the point where the boundary can no longer be described as a simple 2D array of dislocations and becomes a high angle grain boundary (HAGB) (Doherty et al., 1997; Urai et al., 1986). The misorientation angle threshold marking the limit between a LAB and a HAGB depends on the atomic spacing. For olivine, an average threshold value of $15^{\circ}$ is generally considered.

Despite the simple description of SGR recrystallization provided above, many of the underlying processes remain poorly understood (Drury and Pennock, 2007; Huang and Logé, 2016; Sakai et al., 2014). Missing knowledge concerns in particular the transition from LAB to HAGB. A study in calcite using electron backscatter diffraction has observed randomization of the misorientation axes once LABs became HAGBs (Bestmann and Prior, 2003). Is this a general evolution valid for other mineral phases such as olivine? If so, is it solely due to the progressive accumulation of dislocations from the active slip systems or are other processes involved? What are the processes behind this change?
An additional question for low symmetry materials that do not fulfil the Von Mises criterion for strain compatibility, such as olivine, quartz or ice, is: How many slip systems have to be activated to generate a closed subgrain structure that can evolve into a DRX grain? These issues are central for the development of reliable numerical models predicting how DRX affects the microstructure, CPO, and the physical properties of rocks and other polycrystalline materials during ductile (viscoplastic) deformation.

Our goal is to document: (i) How do subgrains form in olivine? (ii) How do they evolve to form new grains? and (iii) How does this process modify the CPO of the rock? For this, we analyse post-mortem electron backscatter diffraction (EBSD) maps of experimentally deformed olivine-rich rocks. This technique allows to simultaneously obtain statistical data on the CPO and disorientations across LAB and HAGB at sample scale with a detailed characterization of the subgrain boundaries (determination of the types of dislocation that compose these boundaries) and of the different types of HAGB.

\section{Methods}

The studied samples are natural peridotites deformed in axial extension at a constant displacement rate of $\sim 10^{-5} \mathrm{~s}^{-1}, 1473 \mathrm{~K}( \pm 2)$, and confining pressure of $300 \mathrm{MPa}( \pm 1)$ using a Paterson-type gas medium triaxial apparatus at the Rock Deformation Laboratory, University of Manchester, UK. Two different starting materials were used in these experiments: coarse-grained dunites from the Balmuccia massif in the Alps ( $>96 \%$ Olivine $\mathrm{Fo}_{82-83}$ ), with either a weak (VS14) or strong (VS15) CPO, and a fine-grained mylonitic harzburgite from Wuqba massif in the Oman ophiolite (75\% Olivine Fo91, 980A87). The dunites display a well-equilibrated polygonal microstructure, with a mean grain size $\geq 1 \mathrm{~mm}$. The harzburgite has a mylonitic microstructure, with a bimodal grain size distribution defined by elongated olivine porphyroclasts up to $1 \mathrm{~mm}$ long and fine-grained equiaxial neoblasts $10-50 \mu \mathrm{m}$ wide.

The present study focuses on DRX. Hence, we selected for post- 
mortem analysis of the microstructure the most deformed samples, with bulk strains $\left(l_{f}-l_{0}\right) / l_{0}$ ranging between 29.6 and $50.1 \%$. These samples exhibit non-uniform deformation with a necking zone where strain and stress concentration led to DRX. We performed a detailed EBSD mapping of one to three strongly recrystallized domains in the necking zone of each sample. The low deformation zone close to the piston of the finegrained mylonite, which preserved the original microstructure of the sample, was also mapped and used as a reference for DRX under natural conditions. The mechanical behaviour and the microstructure evolution of the full experimental dataset are presented in a companion article (Ben Ismail et al., 2021).

\subsection{Electron backscatter diffraction (EBSD) data acquisition}

EBSD maps were performed with a CamScan X500-FE CrystalProbe SEM-EBSD equipped with the Oxford NordlysNano EBSD detector at Geosciences Montpellier (France). Operating conditions were an acceleration voltage of $15 \mathrm{kV}$ and a working distance of 24-25 mm under low vacuum conditions $(\sim 5 \mathrm{~Pa})$. EBSD patterns were indexed using the AZtecHKL software of Oxford Instruments. For EBSD analysis, samples were pre-polished with colloidal silica suspension to remove any damage produced during the mechanical polishing with diamond paste and not carbon-coated. We analysed local maps with step sizes varying between 1 and $2.5 \mu \mathrm{m}$ (mainly $2 \mu \mathrm{m}$ ) covering areas from $716 \times 638$ up to $5365 \times 3456 \mu \mathrm{m}^{2}$. Indexing rates in raw maps range between 72 and $87 \%$ of the surface analysed. Non-indexed pixels are mostly due to fractures produced during sample removal.

\subsection{Electron backscatter diffraction (EBSD) data treatment}

Post-acquisition data treatment was performed using the MTEX toolbox v5.2 or higher (Bachmann et al., 2010; Mainprice et al., 2014) and in-house MATLAB codes provided in Supplementary Material. Wild spikes and orientation data with a mean angular deviation (MAD) above $1.3^{\circ}$ were removed from raw data. Grains were then segmented using a Voronoi decomposition algorithm with the threshold misorientation set to $15^{\circ}$. For the characterization of the misorientation (angle and axis of rotation), we selected the one that produced the smallest rotation angle, that is, the disorientation (Lloyd et al., 1997; Mainprice et al., 1993; Randle and Ralph, 1986; Wheeler et al., 2001). Thus, all misorientation angle/axis pairs in this study are strictly disorientations although the general term misorientation is used to refer to them. For the grain size analysis, grains composed by less than 6 pixels and/or with a fraction of non-indexed pixels above $2 / 3$ were discarded.

\subsection{Discrimination of recrystallized grains and grain boundary types}

Grains were segmented based on two conditions. The grain orientation spread (GOS), which is the average deviation in orientation between each orientation measure within a grain and the average orientation of the grain, was used to discriminate between dynamically recrystallized (DRX) grains (GOS $<2.0^{\circ}$ ) and porphyroclasts (GOS $\geq 2.0^{\circ}$ ). Then, the sectional area (threshold at $\log _{10}\left(\right.$ area in $\left.\mu \mathrm{m}^{2}\right)<4$ ) was used to discriminate remnant grains, which are porphyroclasts leftovers (GOS $\geq 2.0^{\circ}$ ) within recrystallized domains (Fig. 1).

HAGBs were classified into three types: (1) RX-RX HAGBs separate two recrystallized grains, (2) SS-SS HAGBs separate two sub-structured (SS) grains (porphyroclasts or remnants), and (3) SS-RX HAGBs separate sub-structured from recrystallized grains, composing the recrystallization front (for more details see Lopez-Sanchez et al., 2020). These two segmentation procedures allow (1) the comparison of the CPO and microstructural properties between recrystallized and porphyroclasts or remnant grains and (2) the analysis of the features of the different boundary types.
Table 1

Olivine main slip systems and dislocation types for high-temperature deformation.

\begin{tabular}{|c|c|c|c|c|c|}
\hline $\begin{array}{l}\text { Dislocation } \\
\text { type }\end{array}$ & Slip system & $\begin{array}{l}\text { subgrain } \\
\text { boundary }\end{array}$ & $\begin{array}{l}\text { line } \\
\text { direction }\end{array}$ & $\begin{array}{l}\text { Critical } \\
\text { Resolved } \\
\text { Shear } \\
\text { Stress }^{\mathrm{a}}\end{array}$ & Energy \\
\hline Edge & {$[100](010)$} & $\begin{array}{l}\text { tilt LAGB } \\
/ /(100)\end{array}$ & [001] & 1 & $b^{2}$ \\
\hline Edge & {$[100](001)$} & $\begin{array}{l}\text { tilt LAGB } \\
/ /(001)\end{array}$ & [010] & 1 & $b^{2}$ \\
\hline Edge & {$[001](100)$} & $\begin{array}{l}\text { tilt LAGB } \\
/ /(100)\end{array}$ & [010] & 3 & $b^{2}$ \\
\hline Edge & {$[001](010)$} & $\begin{array}{l}\text { tilt LAGB } \\
/ /(001)\end{array}$ & [100] & 2 & $b^{2}$ \\
\hline Screw & $\begin{array}{l}{[100] \&} \\
{[001]} \\
\text { Burger } \\
\text { vectors, any } \\
\text { plane }\end{array}$ & $\begin{array}{l}\text { twist } \\
\text { LAGB // } \\
(010)\end{array}$ & $\begin{array}{l}{[100] \&} \\
{[001]}\end{array}$ & & $b^{2}(1-\gamma)$ \\
\hline
\end{tabular}

${ }^{\text {a }}$ Normalized relative to [100](010), i.e. for $H T$ dry deformation conditions (Tommasi and Vauchez, 2015).

${ }^{\mathrm{b}} b$ - refers to burgers vector and $\gamma$ to the Poisson ratio of olivine.

\subsection{Determination of the dislocation types composing the subgrains walls} (LABS)

EBSD data gives access to information on a part of the total dislocation population in a crystal referred to as geometrically necessary dislocations (GND), which produce the curvature of the crystal lattice; as opposed to the statistically stored (SSD) dislocations, which, due to their random organization produce no lattice curvature at micrometric scales. However, the atomic structures of GNDs do not necessarily differ from that of SSDs. Both are ordinary dislocations impossible to differentiate on an individual basis (Gao and Huang, 2003). Thus, characterization of the GND population allows determining the most common dislocation types (slip system and edge or screw character) stored within a crystal.

GND densities at subgrain boundaries were estimated from the misorientation mapped by EBSD using the Pantleon (2008) approach as coded in MTEX v.5.2. This procedure estimates the GND densities for the different slip systems active in olivine based on the curvature NyeKröner-Bilby (NKB) tensor (Bilby et al., 1958; Kröner, 1958; Nye, 1953) restored from the spatial gradients in misorientation. Specifically, the procedure links the elastic distortions (curvature tensor) with the GND densities produced by different dislocation types based on the minimization of the strain energy:

$\alpha=\sum_{k} \rho^{k} b^{k} l^{k}$

$\alpha=\nabla \beta$

where $\alpha$ is the curvature tensor, $\rho^{k}, b^{k}, l^{k}$ the GND density, the Burgers vector, and the unit line direction of the $k^{\text {th }}$ dislocation types respectively, $\nabla$ the curl operator (i.e. the lattice infinitesimal rotations), and $\beta$ the elastic displacement gradient. The equations above can be solved for edge and screw dislocations of a series of slip systems by enforcing the minimization of the total line energy (L1 norm). The energy of edge and screw dislocations is assumed proportional to $b^{2}$ and $b^{2}(1-\gamma)$, respectively, where $\gamma$ is the Poisson ratio of the material. To avoid overestimation of GND densities due to EBSD measurement artefacts, we reduced the orientation background noise for misorientation values below $1.5^{\circ}$ using a half-quadratic filter (Bergmann et al., 2016; Hielscher et al., 2019; Seret et al., 2019) with the alpha smoothing parameter set to 0.01 and then interpolated the missing data using the spline filter.

Determining dislocation densities from 2D EBSD data has limitations. First, from 2D orientation data only 6 out of 9 lattice curvature terms of the NKB tensor can be determined and, hence, the curvature 

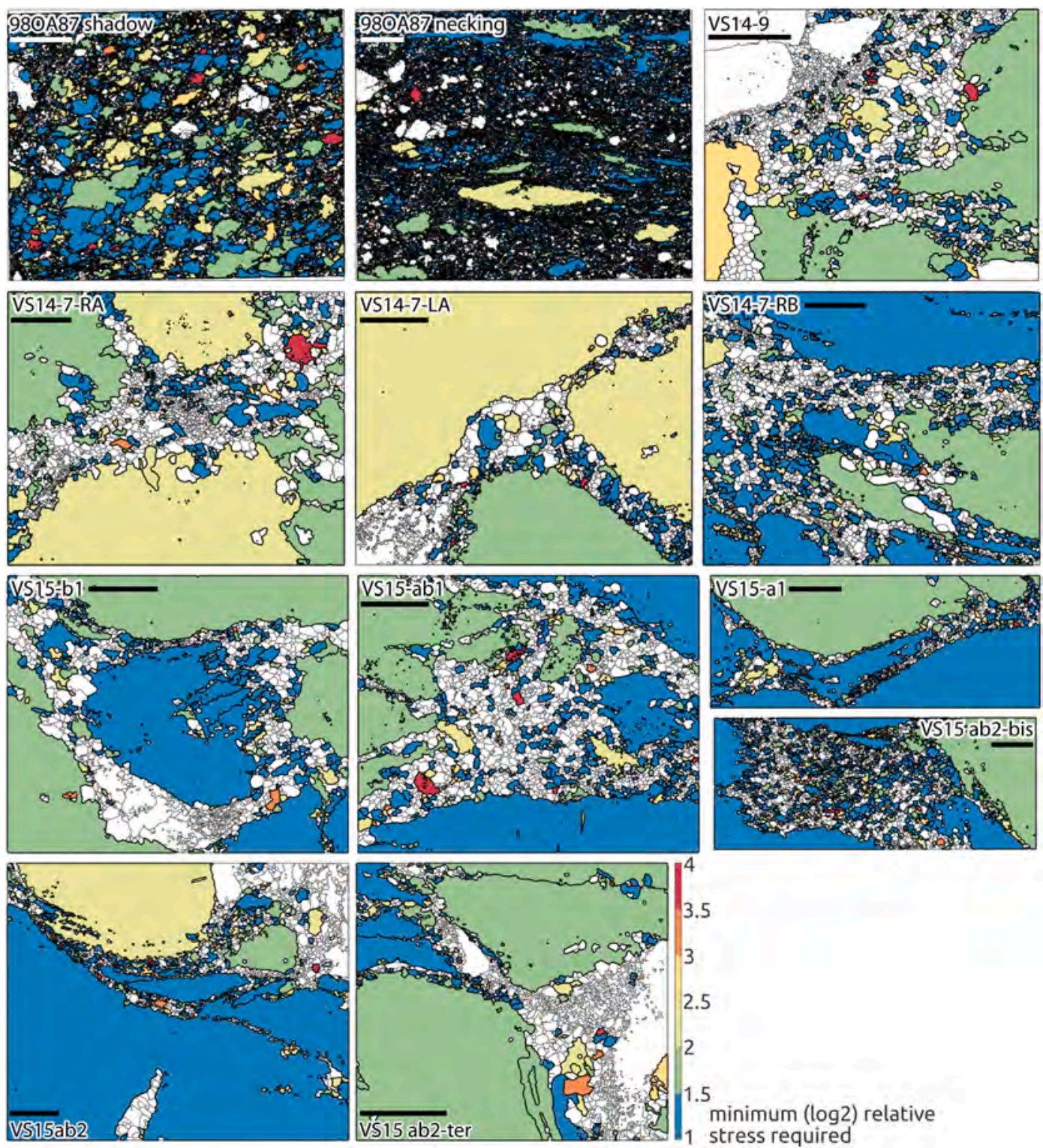

Fig. 2. EBSD maps for the different regions of interest. The colour scale illustrates the relative strength of the non-recrystallized grains relatively to the imposed extension, based on the Schmid factors of the main slip systems of olivine at high-temperature and dry conditions (Tommasi and Vauchez, 2015). It presents the minimum stress normalized by the CRSS of the [100](010) system needed to deform the grain (logarithmic scale). Dynamically recrystallized grains and other mineral phases (enstatite, diopside, or chromite) are displayed in white. All scale bars are $200 \mu \mathrm{m}$ except for sample 980A87, where the scale bar is $1 \mathrm{~mm}$ in the shadow and $500 \mu \mathrm{m}$ in the necking zone. The direction of extension is oriented $E-\mathrm{W}$ in all maps.

tensor is only partially restored. Second, it is assumed that the lattice distortion is completely caused by GNDs that belong to one of the known slip systems in olivine. Third, low dislocation densities producing misorientation angles below the maximum angular resolution (within the range $0.1-0.5^{\circ}$ for conventional EBSD) or that induce lattice distortions that compensate each other below the EBSD operating spatial scale (i.e. the step size) remain undetected. The GND density obtained is therefore a minimum value. Last, for restoring the NBK tensor it is necessary to define the energies of all active dislocation types. For olivine, the energies for edge and screw dislocations of the main active slip systems are constrained from studies using TEM and oxidationdecoration techniques (Bai and Kohlstedt, 1992; Darot and Gueguen, 1981; Durham et al., 1977; Goetze and Kohlstedt, 1973; Gueguen, 1979; Jaoul et al., 1979; Kirby and Wegner, 1978; De Kloe, 2001; Mussi et al., 2017; Phakey et al., 1972). These values are listed in Table 1.

Despite the limitations of the technique, Guo et al. (2020) showed that GND densities obtained minimizing the total line energy of the 2D lattice curvature tensor correlate well with 3D GND density measurements obtained by Differential Aperture X-ray Laue Micro-diffraction, which enables the measurement of the full (9-component) Nye lattice curvature tensor. Thus, the present method provides relative values of the GND density proportional to the misorientation whenever the latter is higher than the angular resolution of the EBSD system. Here we use this method to analyse subgrain walls with misorientations above $1.5^{\circ}$, a value well above the angular resolution of the EBSD system. Besides, the low number of active slip systems in olivine (Table 1) limits the ambiguity in relating the different components of the curvature tensor to specific dislocation types. This makes the method suitable for the study of GNDs populations within LABs in olivine.

\subsection{Schmid factors analysis: minimum stress and slip system IPF maps}

Based on the Schmid factor of the main slip systems in olivine and on their relative critical resolved shear stresses (CRSS; Table 1), we 

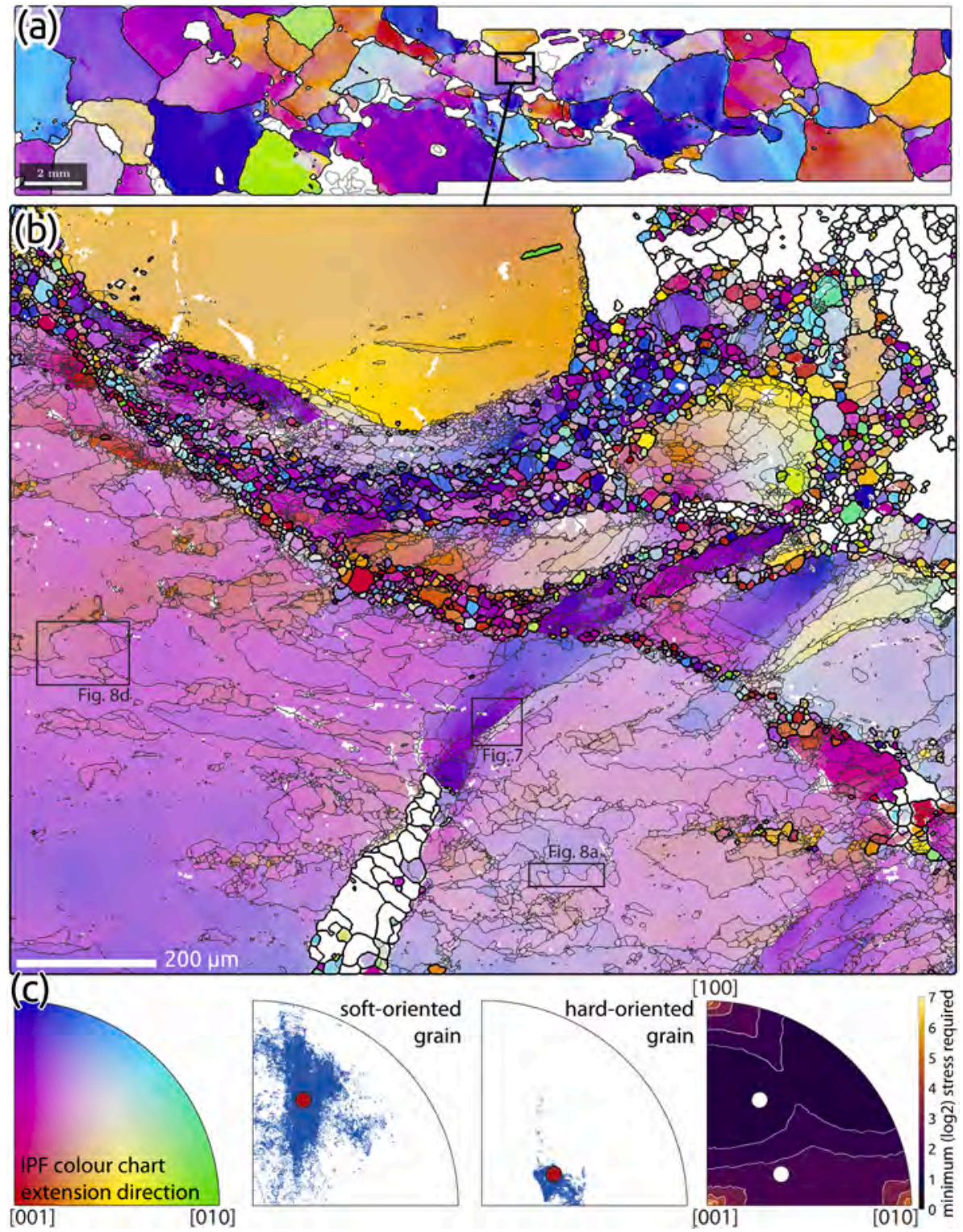

Fig. 3. Sample VS15ab2. (a) Sample-scale EBSD map (step size $40 \mu \mathrm{m}$ ) indicating the location of the high spatial resolution map displayed in (b). Olivine is coloured as a function of the orientation of the imposed extension relative to the crystal orientation inverse pole figure (IPF) colour scheme presented in (c). Pyroxenes and spinels are displayed in white. (b) High-resolution EBSD map (step size $2 \mu \mathrm{m}$ ) showing the contact between a porphyroclast in a hard orientation (yellow) and one in a soft orientation (pinkpurple), which is strongly sub-structured and recrystallized. Thick black lines define grain boundaries (misorientation $\geq 15^{\circ}$ ) and fine grey lines subgrain boundaries with misorientations $\geq 1^{\circ}$. Same colour scheme as (a). (c) IPFs relative to the extension direction (x). From left to right: (1) the colour scheme for the representation of the olivine crystals orientation in (a) and (b), (2) the crystal orientation distribution (mode in red and all EBSD data in blue) in the soft porphyroclast (no DRX or remnant grains included), (3) the crystal orientation distribution in the hard oriented porphyroclast, and (4) values of minimum stress needed to activate the weakest slip system, which is function of the orientation of the grain relative to the imposed extension, considering CRSS typical of deformation of olivine at hightemperature, dry conditions (Table 1). Stresses are plotted using a base 2 logarithmic scale (i.e. olivine orientations along a given contour line require twice or half the stress to be deformed relative to the adjacent contour). The hard grain requires stresses more than four times higher than the soft one to deform at similar strain rates. (For interpretation of the references to colour in this figure legend, the reader is referred to the web version of this article.) generated minimum stress and preferred slip system inverse pole figure (IPF) maps using in-house Matlab codes provided in the Supplementary Material. The procedure to estimate the minimum stress (normalized by the CRSS of the weakest slip system) required for plastic deformation of a crystal with a given orientation relative to the imposed stress field and the dominant and subdominant slip systems within the IPF space were as follows:

1) A large number $\left(10^{5}\right)$ of olivine random orientations are generated to uniformly cover all possible orientations in the IPF space.

2) The slip systems expected to be active in olivine (Table 1) including all symmetrically equivalent slip planes, their CRSS values for hightemperature deformation conditions, and the extension direction are defined.

3) Based on this data, we estimate the Schmid factor $(S)$ using the SchmidFactor function implemented in the MTEX for each slip system in each of the random orientations generated using

$$
S=\cos \Psi \cos \lambda
$$

where $\cos \Psi$ is the direction cosine between the direction of the applied force and the slip direction and $\cos \lambda$, the direction cosine between the direction of the applied force and the slip plane normal.

4) For each orientation, we estimate the (dimensionless or relative) stress required to deform a grain with this orientation using the ratio between the CRSS value and the Schmid factor for each slip system, and the minimum value among the different slip systems is extracted.

5) Minimum stress values for different orientations are plotted in an inverse pole figure contoured using a logarithmic scale with base 2 so that each contour line represents grain orientations that require twice or half the stress to deform by dislocation glide than the adjacent contour.

6) For the favoured slip system maps, the IPF space is segmented based on the two slip systems that require the lower stresses for the considered orientation.

In reality, all slip systems contribute to the deformation of a crystal proportionally to their activity. The present approach provides a firstorder estimate of the strength and most active slip systems in a crystal under the assumption that the bulk (macroscopic) stress largely 


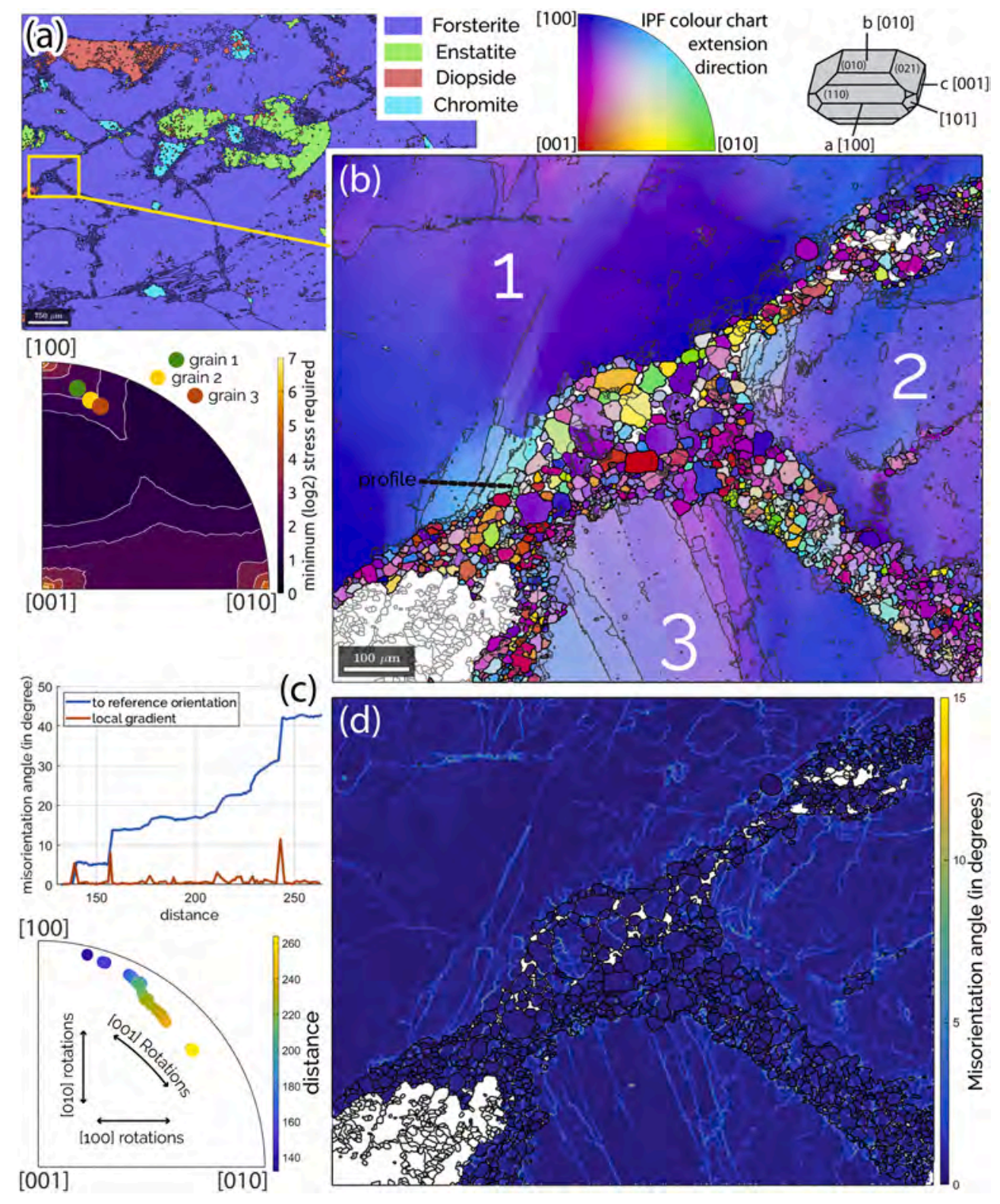

Fig. 4. Sample VS14-7-LA. (a) Sample-scale EBSD phase map (step size $30 \mu \mathrm{m}$ ) indicating the location of the high spatial resolution map displayed in (b) and (d). (b) Highresolution (step size $2 \mu \mathrm{m}$ ) EBSD orientation map displaying three porphyroclasts in relatively hard orientations with respect to the extension direction (especially the grain 1 , cf. IPF stress map on the left) separated by a recrystallized domain. Olivine is coloured as a function of the orientation of the imposed extension, which is horizontal in the plane of the map, relative to the crystal orientation, cf. IPF colour legend at the top. Thick black lines are grain boundaries (misorientation $\geq 15^{\circ}$ ) and fine grey lines subgrain boundaries with misorientations $\geq 1^{\circ}$. (c) Profiles of misorientation angle and axis in grain 1 . The accumulation of subgrain tangles produces a cumulated misorientation angle $>40$ degrees and a shift towards softer orientations over a distance of $\sim 100 \mu \mathrm{m}$. Note that the shift in orientation is mainly due to rotation around [001]. (d) Kernel average misorientation (KAM) map revealing the arrangement of the subgrain boundaries. Note the higher subgrain density close to the recrystallization front.

predominates over the local stresses associated with grain interactions.

\section{Results}

Analysis of the ensemble of detailed EBSD maps in the originally coarse-grained dunites, where the newly recrystallized grains may be easily identified, shows that DRX occurs essentially at the contacts between olivine grains with different strength, due to variations in orientation relative to the imposed stretching, or olivine grains in contact with pyroxenes (Fig. 2). Subgrains (misorientations across the boundary $<15^{\circ}$ ) develop mainly in olivine grains in soft orientations relative to the imposed extension. By grains in soft orientations, we refer to grains oriented in such a way that they may deform mainly by activation of the two weakest slip systems (Table 1 ), which corresponds to a minimum dimensionless stress equal to or less than $\log _{2}(1.5)$. In Fig. 2 these grains are coloured in blue. Dynamically recrystallized (DRX) grains develop primarily near the boundaries that put these soft grains in contact with olivine grains in hard orientations or pyroxenes. Fig. 3 shows an example where DRX grains developed in a soft-oriented olivine grain (the purple-pink one) within a volume $<300 \mu \mathrm{m}$ away from the contact

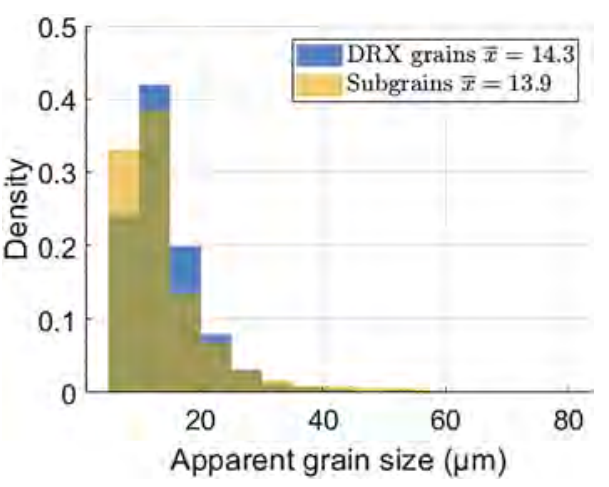

Fig. 5. Comparison of apparent recrystallized grains and subgrain cells size distributions in the region of interest VS15ab2 (Fig. 3b). Note the comparable values of the arithmetic mean size. Protocols used in this analysis are provided in the Supplementary material. 

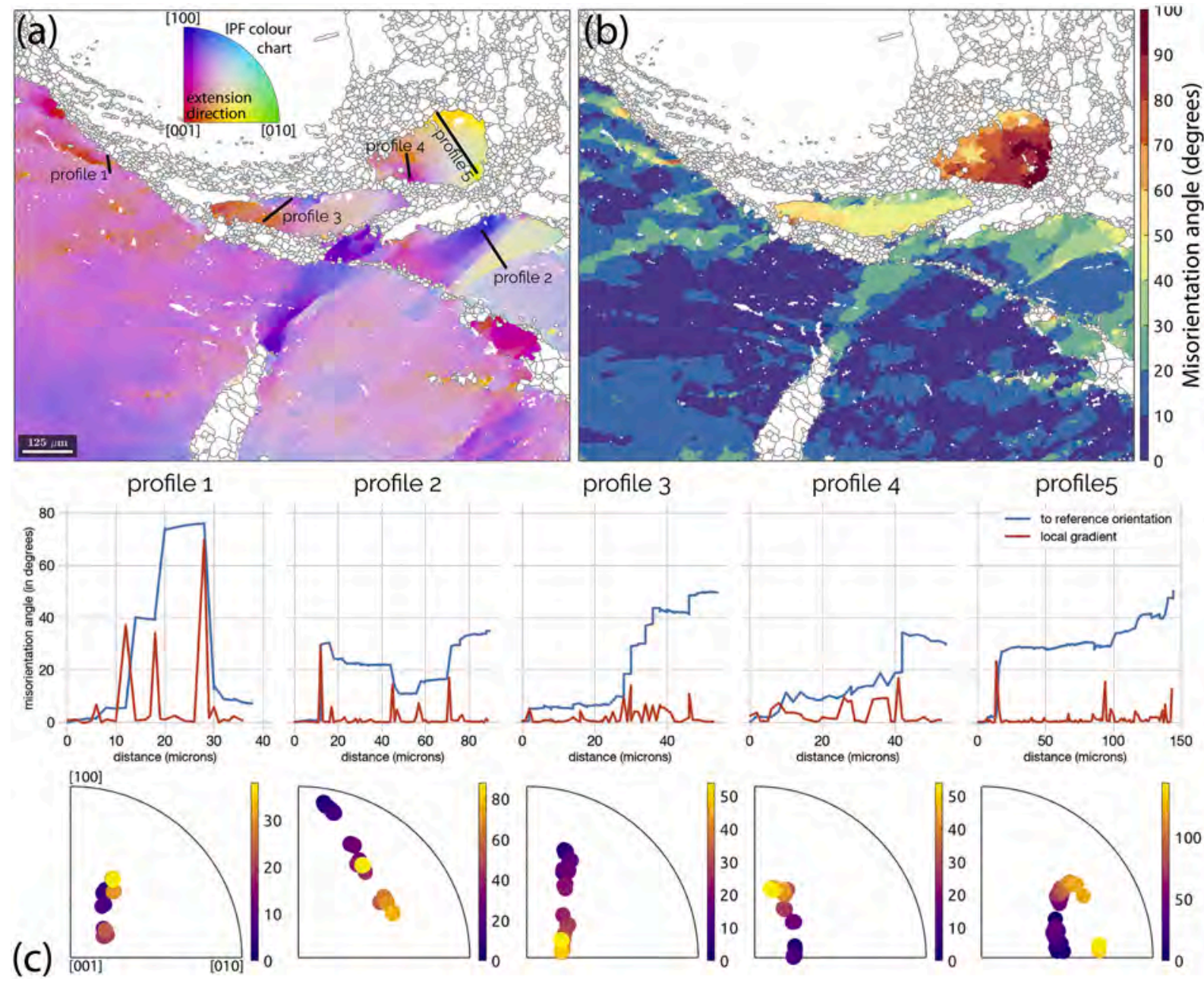

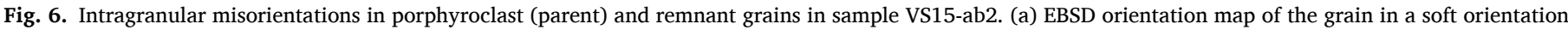

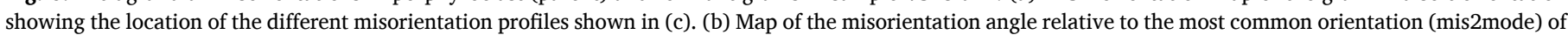

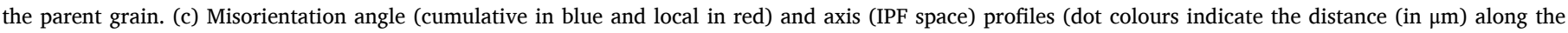

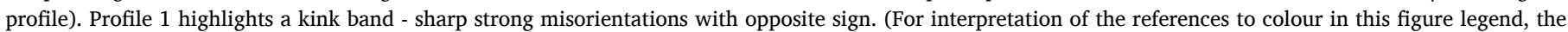
reader is referred to the web version of this article.)

with a hard olivine grain (the orange one) and with a clinopyroxene aggregate (in white). Olivine grains in hard orientations, as the orange grain in Fig. 3 and the dark blue one in Fig. 4, usually have low intragranular misorientations and hardly develop subgrains except nearby $(<50 \mu \mathrm{m})$ the boundary (Fig. 4b, d). DRX grains have dominantly equant polygonal shapes (Fig. 1). Subgrain cells and DRX grains have similar grain size distributions (Fig. 5). DRX grains have dominantly equant polygonal shapes (cf. Fig. 1), a feature typical of subgrain rotation recrystallization.

The porphyroclast display strong cumulative intragranular misorientations (up to $80^{\circ}$ ) due to the addition of LABs (cf. IPF colour changes in Fig. 6a, misorientation profile in Fig. 4c and profiles $2-5$ in Fig. 6). In some subgrain walls, misorientations are locally higher than $15^{\circ}$, forming intragranular high-angle boundaries (e.g. profiles $2 \& 5$ in Fig. 6). Most of these intracrystalline misorientation gradients result from rotations around low Miller indices crystallographic axes, especially [010] and [001] or combinations of these (Figs. 4c \& 6c; see more evidence of this phenomenon in Figs. 7 to 10). Fig. 6 b illustrates how the accumulation of subgrain walls within a parent grain may lead to cumulative angle misorientations of $>60^{\circ}$ to the most common orientation (mode) of the parent grain (the original orientation cannot be recovered as this is a post-mortem EBSD analysis). It also shows that the remnants of this porphyroclast enclosed within the recrystallized domain reach misorientation angles close to the maximum possible for an orthorhombic crystal $\left(120^{\circ}\right)$. Profile 1 in Fig. 6 c illustrates an additional type of planar defect that develops in highly stressed areas: kinks, which accommodate sharp strong misorientations with opposite signs. Kinks in soft-oriented grains, like the one presented in Fig. $6 \mathrm{~b}$, are rare. They are nevertheless common in grains in hard orientations (Ben Ismail et al., 2021).

\subsection{Low-angle $\left(<15^{\circ}\right)$ boundaries}

Low-angle boundaries either display a straight intersection with the analysis surface, suggesting a planar shape, or have irregular shapes forming cells. Most straight LAB traces run normal to the [100] axis (Figs. 3, 7). GND density analysis indicates that they are mainly formed by edge dislocations of the [100](010) slip system (Fig. 7c), which is the easiest glide system in olivine under the experimental conditions, and edge dislocations of the [100](001) system. They also contain variable densities of edge dislocations of the [001](001) and [001](010) systems and [100] and [001] screws. These LABs yield misorientation axes close to [001] when edge dislocations of the [100](010) system predominate or spread between [001] and [010] when the contribution of edge dislocations of the [100](001) system increases (Fig. 7b). The scatter in the IPF charts illustrating the rotation axes in the LABs for misorientation 


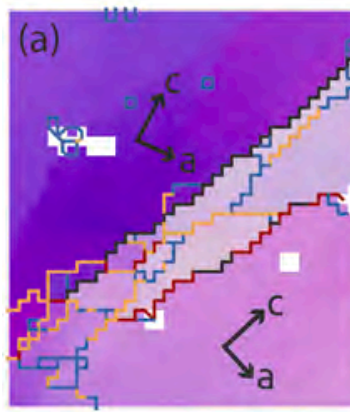

Misorientation angle
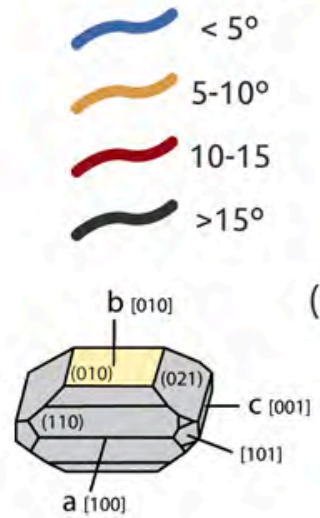
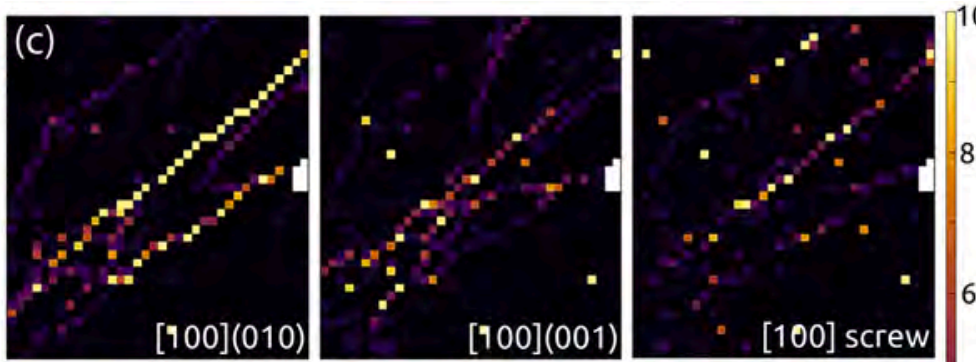

10
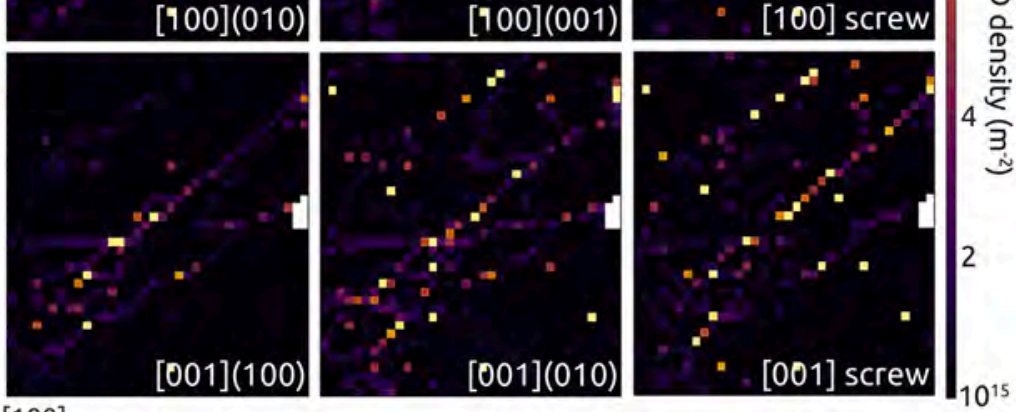

[100]

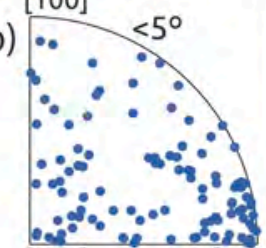

[001]

[010]
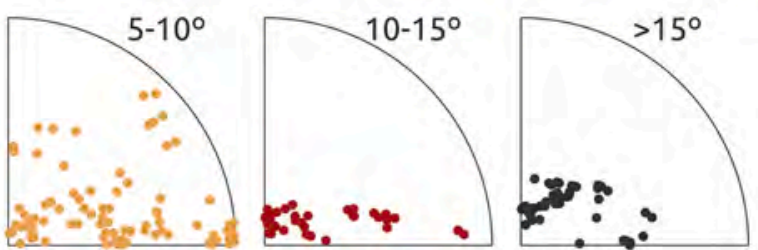

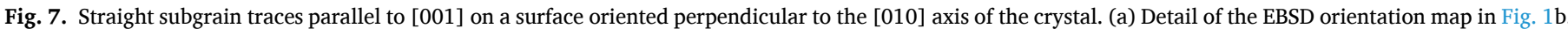

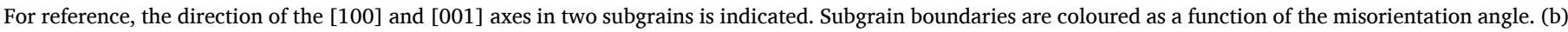

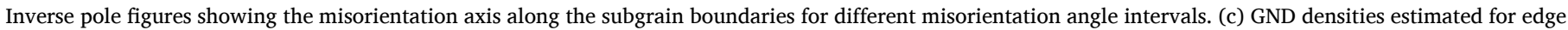
and screw dislocations of the main slip systems in olivine.

angles $<5^{\circ}$ results from the limitation of EBSD to accurately resolve rotation axes for misorientation angles $<2^{\circ}$ (Prior et al., 1999; Wilkinson, 2001).

Irregularly-shaped LAB traces predominate within the highly strained grains (Fig. 3b). These LABs display zig-zag or closed-circuit patterns (Fig. 8), although some long segments normal to [101] are observed on surfaces oriented perpendicular to [010] (Figs. 3b, 8d). Analysis of the GND density indicates that these irregularly shaped LABs are essentially formed by edge dislocations of the [100](001) and [001] (100) slip systems (Fig. 8c,f). When the LAB traces run normal to [100], they are mainly formed by accumulations of edge dislocations of the [100](001) slip system, whereas those normal to [001] are mostly formed by edge dislocations of the [001](100) slip system. Alternation of these two types of tilt walls produces the observed zig-zag pattern (Fig. 8c). When the LAB trace is oblique to [001] and [100] axes, edge dislocations of both slip systems contribute in varying degrees. Independently of the orientation of the LAB trace, the misorientations across these irregularly-shaped LABs are characterized by rotation axes roughly parallel to [010] (Fig. 8b, e).

The least common among the observed LABs are those largely composed by edge dislocations of the [001](010) slip system (white arrow in Fig. 9a,b). They usually appear as short LABs closing subgrain cells in combination with LABs of the most common types, and are characterized by rotation axes close to [100] (Fig. 9c).

\subsection{The transition from low-angle ( $L A B$ ) to high-angle grain boundaries (HAGB)}

We analyse the transition from LAB to HAGB by comparing the misorientation axes that characterise them (Figs. 10 and 11). For the HAGB, we analyse separately: (1) those belonging to the recrystallization front (RX-SS), (2) those separating DRX grains (RX-RX), and (3) those separating sub-structured (porphyroclasts and remnants) grains (SS-SS). In samples VS14 and VS15, the areas of interest were originally composed of two to four olivine grains (Fig. 2). This means that most, if not all, of the characterized HAGB correspond to boundaries developed during deformation and, thus, to boundaries that were previously LABs.

Inverse pole figures (IPFs) of misorientation axes across LABs systematically display a misorientation peak parallel to [010] in all samples. The intensity of this peak varies strongly, ranging from $\sim 3.5$ up to $\sim 17$ multiples of a uniform distribution (e.g. VS14-7 or VS15ab2 in Fig. 10). As illustrated in Section 3.1, a misorientation axis close to [010] is linked to tilt walls formed by the accumulation of dislocations of the [100](001) and [001](100) slip systems. This peak in misorientation axes agrees with the predominance in the studied zones of irregularlyshaped LABs composed by dislocations of these two slip systems (Figs. 3, 8). In addition, most IPFs of misorientation axes across LABs show a sub-maximum located around [001], which is related to the planar tilt walls mainly composed by edge dislocations of the [100] (010) system (Figs. 3, 7). The intensity of this secondary peak varies between $<1$ up to $\sim 2$ multiples of a uniform distribution. Only one region of interest among all those studied (sample VS14-9) displays a submaximum around [100], related to tilt walls dominated by edge dislocations of the $[001](010)$ system. Overall, the occurrence of the different LAB types portrayed in Section 3.1 agrees with the bulk misorientation axis distributions observed in the inverse pole figures.

When focusing on the recrystallization front, the misorientation axis distribution changes severely. First, there is a spread in the misorientation axis distribution associated with the decrease in importance or even the disappearance of some of the maxima typical of the LABs and the appearance of other maxima. In all cases, there is a sharp decrease in the intensity of the maximum around [010] compared to LABs; in RX-SS HAGB, this maximum is systematically below 2 multiples of a uniform distribution (Fig. 10). However, there is not a unique evolution path. 

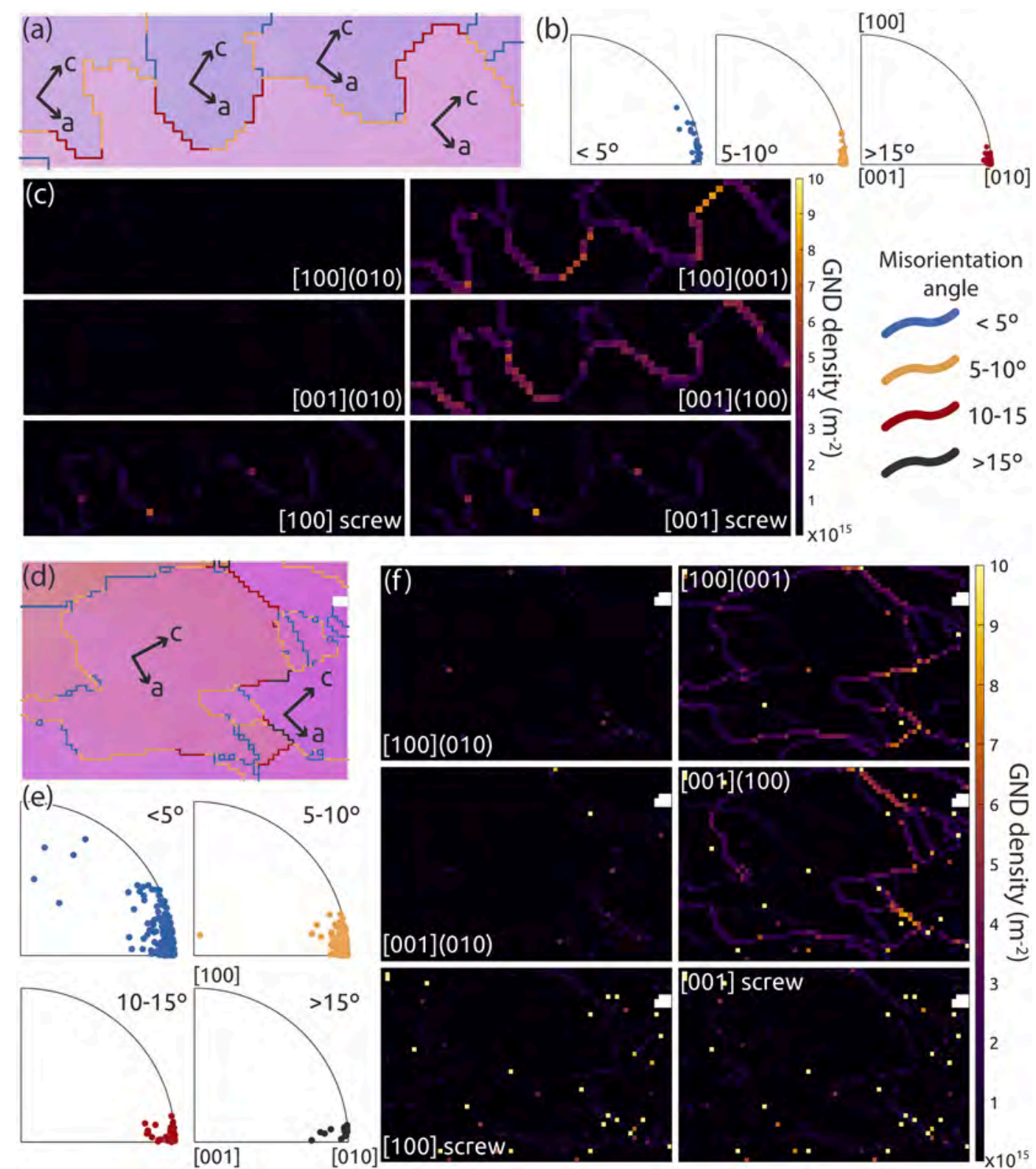

Fig. 8. Examples of irregular (closed-loop and zig-zag) tilt subgrains boundaries on a measurement surface perpendicular to [010]. (a, d) EBSD IPF orientation maps of two regions of interest. The orientation of the [100] and [001] axes in different subgrains is indicated for reference. Subgrain boundaries are coloured as a function of the misorientation angle range. (b, e) IPF showing the misorientation axis across the subgrains boundaries for different misorientation angle intervals. (c, f) GND densities estimated for edge and screw dislocations of the main slip systems in olivine. Note the high density of edge dislocations of the [100](001) and [001](100) systems and the systematic variation in the density of GNDs of each system as a function of the orientation of the subgrain boundary.

Sometimes, as in samples VS14-7 and VS14-9 (Fig. 10), the transition from $L A B$ to HAGB results in the dispersion of the maxima that dominated in the LABs. In other cases, there is an abrupt change in the misorientation distribution with the development of a new maximum around $\langle 101\rangle$. The analysis of the misorientations across HAGB between DRX grains (RX-RX HAGB) shows further scattering without major contrast relative to the recrystallization front, indicating a continuous evolution (Fig. 10). The occasional discontinuous HAGBs within the porphyroclasts also display scattering of the misorientation rotation axes relatively to the LABs, but the scattering is weaker than that observed for the recrystallization front (Fig. 10).

The misorientation angle distribution for HAGB within the porphyroclasts shows frequently, though not always, a peak in misorientation values below 40 degrees. In contrast, the misorientation angle distributions for HAGB composing the recrystallization front (RX-SS boundaries) display dominantly flat profiles (Fig. 11), although there is some variability among the study areas. Samples VS14-9, VS15-a1 and VS15-ab1 show fairly flat misorientation profiles between 20 and 90 degrees, while VS15-b1 shows an asymmetric profile with decreasing frequencies towards high misorientation values ( $>60$ degrees). Interestingly, samples VS14-7 and VS15-ab2, with three different analysed zones in each, show the three possible misorientation profiles: flat, decreasing and increasing towards high misorientation values. The misorientation angle distribution for HAGB separating DRX grains is similar to that of the RX front, but RX-RX boundaries tend to show higher frequencies for high misorientations with a peak around 90 degrees.

Detailed analysis of some examples of closed-loop HAGBs highlights GND densities an order of magnitude higher than that in LABs (Fig. 12). It also points to a higher frequency of screw dislocations compared to 


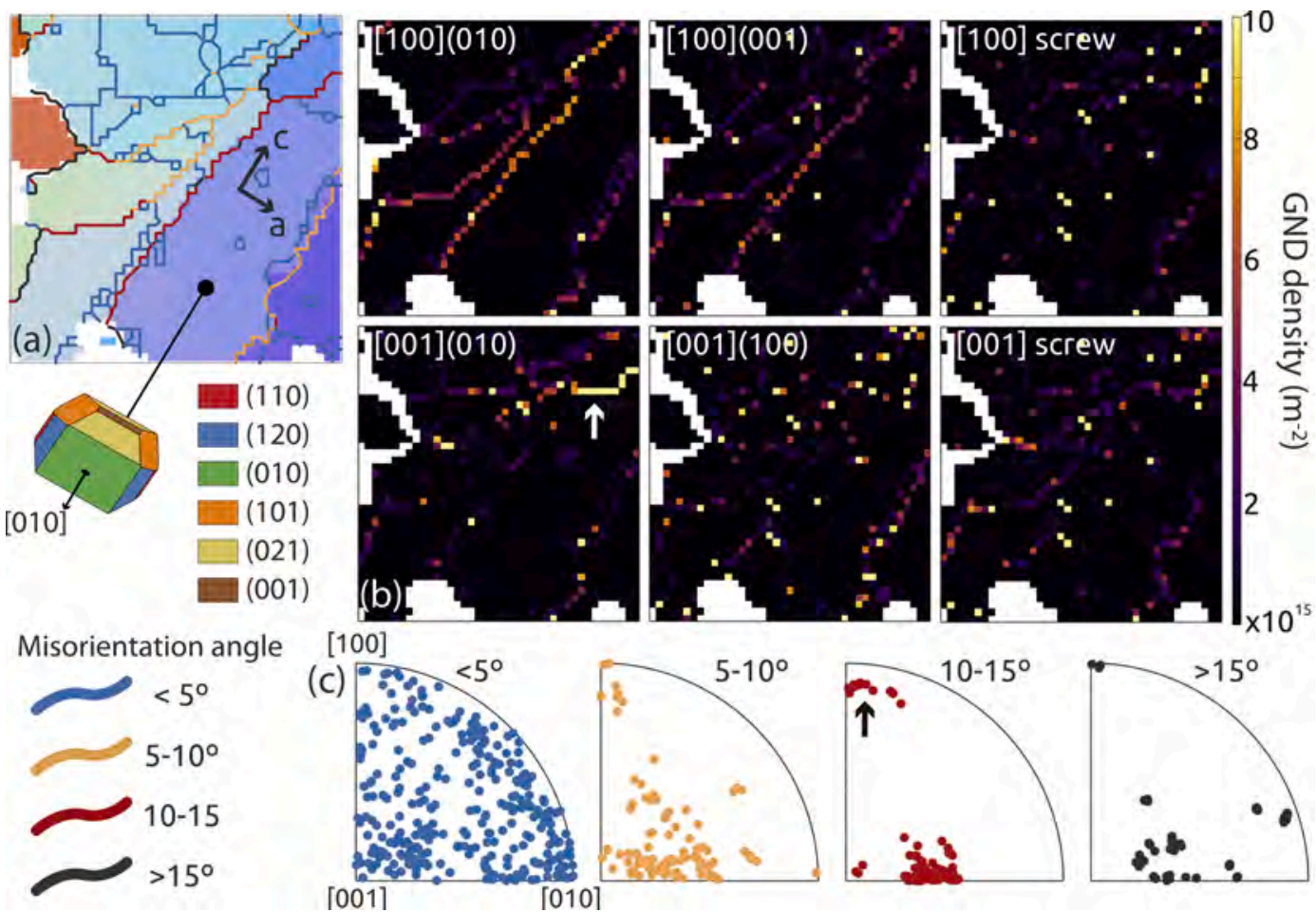

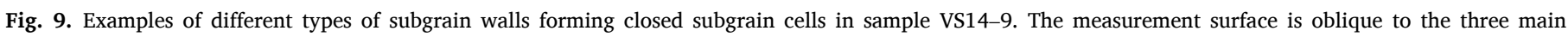

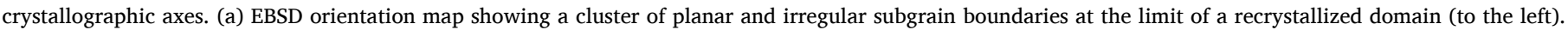

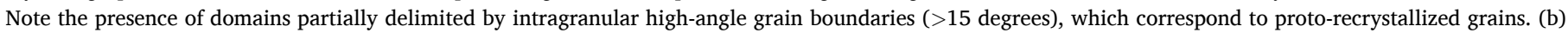

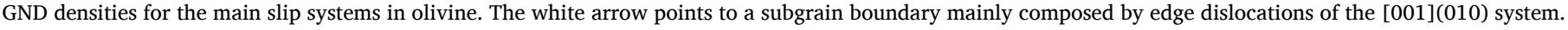

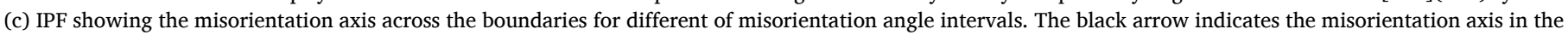
subgrain boundary segment dominated by edge dislocations of the [001](010) system.

LABs. However, this inference might be biased by the fact that we impose in this analysis that all curvature gradients are explained by GNDs of the 4 slip systems supposed to be the most active during deformation of olivine under high temperature, low pressure, and dry conditions (Table 1).

\subsection{Effect of $D R X$ on the crystallographic preferred orientation}

Most parent grains in the regions of interest have their [100] axes within 10-45 degrees to the extension direction (Fig. 13), with a predominance of crystals oriented with the $\langle 101\rangle,\langle 111\rangle$, or $\langle 110\rangle$ axes close to the extension direction. This is consistent with the fact that we focused the observations on strongly recrystallized domains and that recrystallization is favoured in grains with soft orientations (Figs. 2, 3). Porphyroclasts with different orientations display little or no recrystallization (Figs. 2, 3).

Analysis of the IPFs for the remnant and DRX grains shows that SGR recrystallization produces a marked dispersion in the crystal orientations (Fig. 13). This spread is mainly associated with rotations around the [010] axis, leading to dispersion of the crystals orientations along with small circles normal to this axis. However, other rotations are also involved. In most cases, maxima of $\langle 101\rangle$, [100], $\langle 110\rangle$, or $\langle 111\rangle$ axes close to the extension direction are still present, though they are weak, in particular for the DRX grains.

\section{Discussion}

High-resolution EBSD mapping of recrystallized domains in natural peridotites deformed in axial extension at $1473 \mathrm{~K}$ and strain rates around $10^{-5} \mathrm{~s}^{-1}$ shows that DRX occurred in the necking region. In this region, DRX developed preferentially in olivine grains in soft orientations relative to the imposed extension, which are in contact with olivine grains in hard orientations or pyroxenes. These observations indicate that DRX is favoured by the association of high strain and local stress concentrations. Besides, the gradual transition from subgrain to DRX grains and the similarity in shape and size distribution between subgrain cells and DRX grains indicate that DRX results essentially from subgrain rotation (SGR).

\subsection{Subgrain formation (low-angle boundaries $<15^{\circ}$ )}

The analysis of the GND content (Figs. 7-9) and the misorientation axes (Fig. 10) indicates that subgrains are essentially delimited by tilt low-angle boundaries (LAB) composed by edge dislocations of the main active slip systems in olivine at high-temperature conditions: [100] (001), [001](100), [100](010), and [001](010) in order of decreasing frequency. Overall, these observations agree with the transmission electron microscopy observations by Kirby and Wegner (1978) in peridotite xenoliths, which describe olivine tilt walls composed by dislocations of the same systems in the same order of diminishing importance. In addition to these tilt walls, transmission electron microscopy studies have also observed twist walls parallel to (010) composed of screw dislocations with [100] and [001] Burger vectors (Darot and Gueguen, 1981; De Kloe, 2001; Phakey et al., 1972; Ricoult and Kohlstedt, 1983), which were not reliably characterized in our samples because of the twodimensional nature of EBSD data.

The prevalence in the LABs of edge dislocations of the [100](001) and [001](100) slip systems over those of the [100](010) system is at odds with mechanical data for olivine single-crystals (Bai et al., 1991), which show that [100](010) is the weakest system at the conditions of the present experiments. It is also at odds with the analysis of olivine $\mathrm{CPO}$ in naturally deformed peridotites, which also points to the dominant activity of [100](010) during deformation at high-temperature low-pressure conditions (cf. review by Tommasi and Vauchez, 2015). 


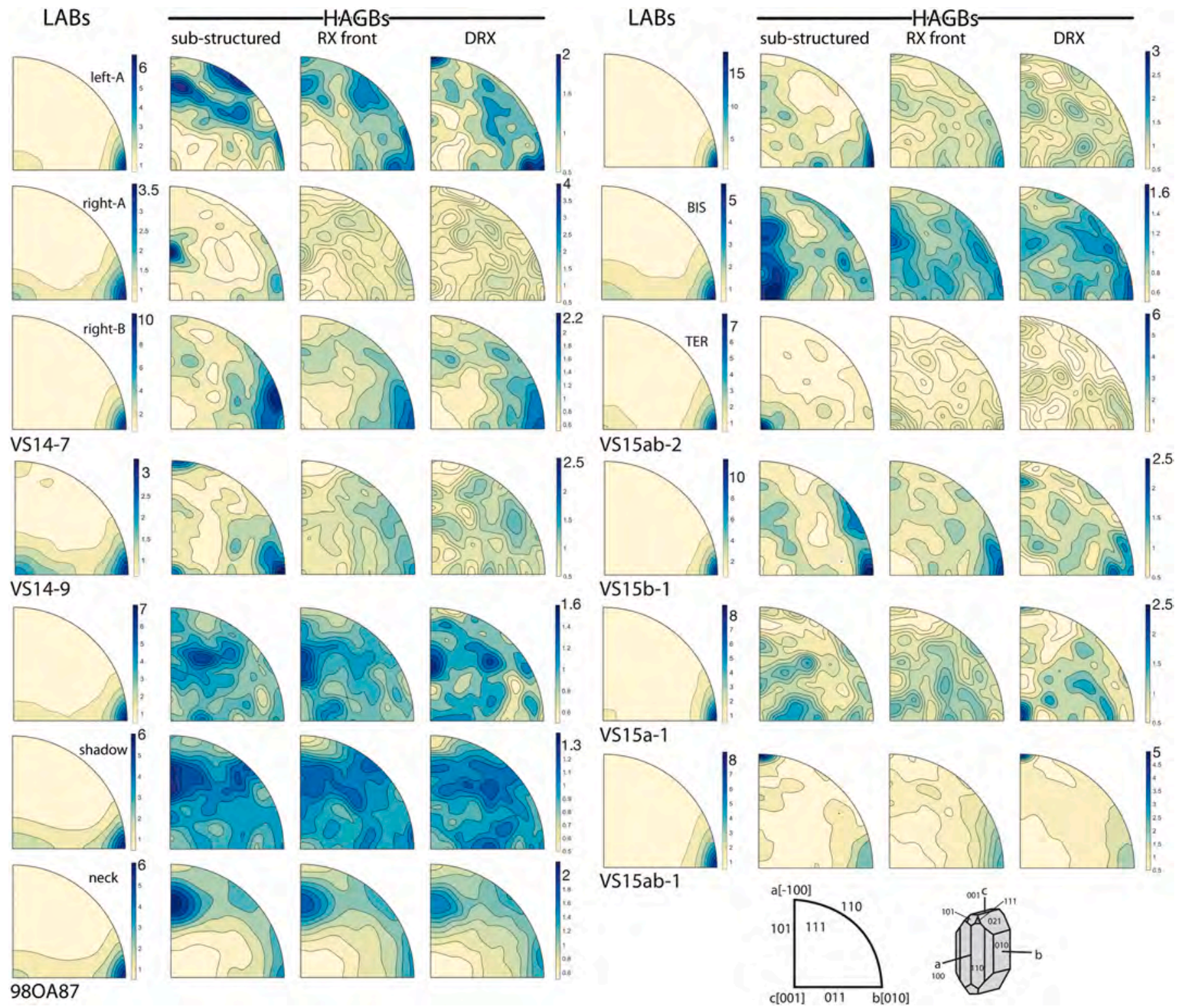

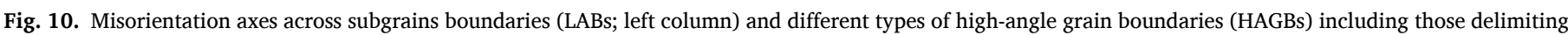

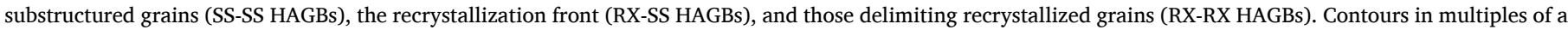
uniform distribution (linear scale).

The IPF maps of most favourable slip systems based on the Schmid factors in Fig. 14 account for all dislocation types observed in the different regions of interest, but not for their proportionality. For example, the range of orientations of the parent grain in Fig. 3 spreads among IPF regions that have different pairs (dominant and subdominant) of favourable slip systems (dashed contour in Fig. 14b). The dominant orientation of this grain lies approximately at the boundary between the domains in which the subdominant slip system changes from [001](100) to [100](010). This agrees with the observation of edge dislocations of both the [100](001) and [100](010) systems forming planar LABs normal to [100] (Figs. 7c and 9c). However, the zig-zag and closed-loop LABs, which are the most common LABs in this grain (Figs. 3 and 8 ), are composed dominantly by edge dislocations to the [100](001) and [001](100) systems (Fig. R07). Formation of these LABs requires the activation of [001](100), a "hard" slip system, and thus high stresses.

The observations described above corroborate that the activity of the different slip systems is not proportional to their occurrence in the LABs. This hypothesis had been previously proposed to account for the discrepancy between olivine CPO, which point to dominant activity of [100](010) during deformation, and misorientation axes across LABs in naturally deformed peridotites, which often display a maximum close to [010] (Soustelle et al., 2010). High-resolution digital image correlation studies in metals presented indeed strong evidence that the unimpeded motion of slip bands through a crystal can accommodate strain producing almost no local misorientation (Harte et al., 2020). Thus, a crystal well-oriented to deform by single-slip and not subjected to strict boundary conditions should develop no LABs and hence not recrystallize by SGR. However, in a real rock composed of highly anisotropic crystals, such as olivine, the grains interact with neighbours in different orientations and thus with different strengths. These interactions, which are submitted to strain compatibility constraints result in local stress concentrations and activation of other slip systems, playing an essential role in the development of LABs and hence in DRX. 


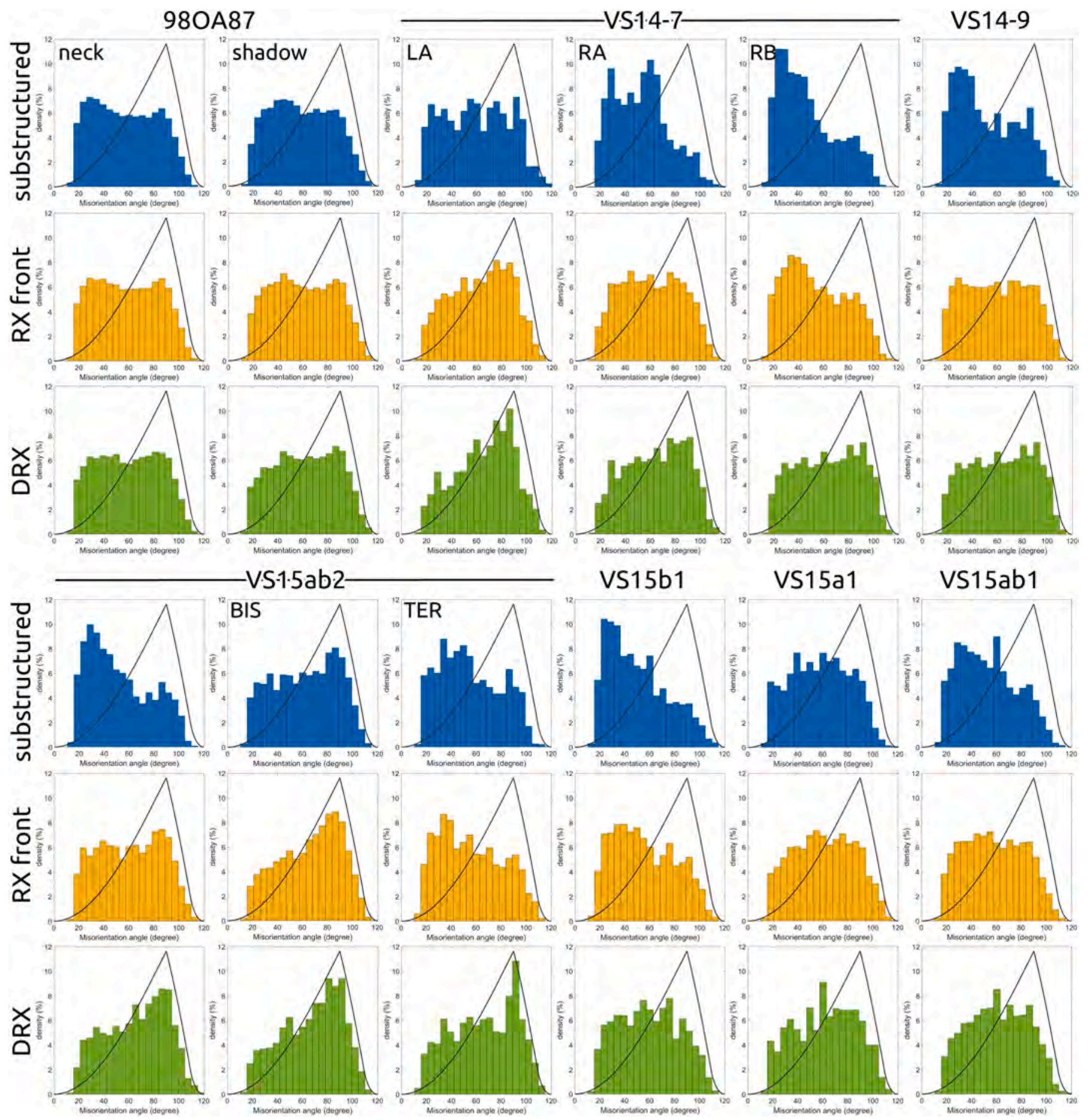

Fig. 11. Correlated misorientation angle distributions across different types of high-angle grain boundaries (HAGB; $>15$ degrees) including those delimiting substructured grains (SS-SS HAGBs), the recrystallization front (RX-SS HAGBs), and those delimiting recrystallized grains (RX-RX HAGBs). Black lines show the theoretical distribution of misorientation angles in an olivine polycrystal with a random $\mathrm{CPO}$ for reference.

\subsection{The formation of recrystallized grains by SGR}

The development of a recrystallized grain requires a threedimensional grain boundary structure. The most common LABs in our samples (zig-zag and closed-loops) are composed of different proportions of edge dislocations of the [100](001) and [001](100) systems (Fig. 15). These LABs share a common misorientation axis around [010] regardless of the direction of the trace and produces LABs with $\{h 0 l\}$ orientations that may result in closed-loop LABs on surfaces oriented perpendicular to [010] (Fig. 8). However, a family of planar LABs intersecting on a common axis do not suffice to generate closed 3D cells unless the LABs crosscut the entire grain (Fig. 15). The combination of these LABs with planar LABs parallel to (100) formed by edge dislocations of the [100](010) and [001](010) systems would also not be able to create closed 3D subgrain cells for the same reason (Fig. 15). The generation of full $3 \mathrm{D}$ subgrain cells thus requires the formation of $\mathrm{LAB}$ planes producing misorientations around [010]. Such LABs are commonly observed in transmission electron microscopy studies. They are twist walls parallel to (010) composed of screw dislocations with [100] and [001] Burger vectors (Darot and Gueguen, 1981; De Kloe, 


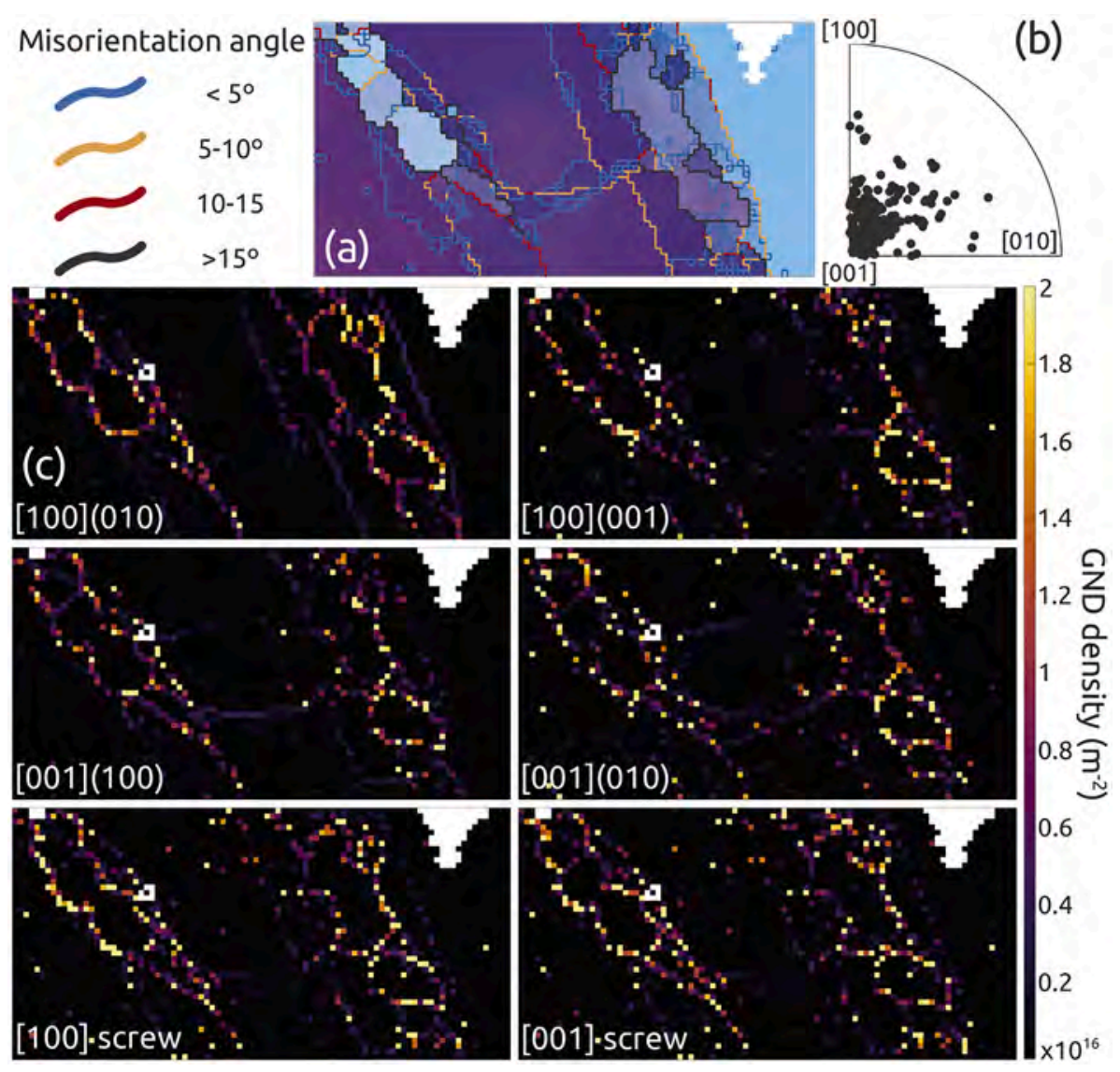

Fig. 12. Closed-loop HAGBs $\left(>15^{\circ}\right)$ showing different types of edge and screw dislocations in sample VS15ab2 (a) EBSD orientation map of the region of interest with the boundaries segmented according to their misorientation angle. (b) Inverse pole figure showing the misorientation axis along the highangle grain boundaries. (c) GND densities for edge and screw dislocations of the main olivine dislocation systems. The presence of screw dislocations is accentuated in HAGBs relatively to LABs (cf. Figs. 7-9). Note that the GND density in HAGB is almost an order of magnitude higher than in LABs $\left(10^{16}\right.$ vs $\left.10^{15}\right)$.

2001; Phakey et al., 1972; Ricoult and Kohlstedt, 1983). In the present study, we did not observe these twist walls probably due to the 2D nature of the EBSD data. We detected- some contribution of screw dislocations to the straight LABs, which are dominantly composed by edge dislocations of the [100](010) and [001](010) slip systems (Figs. 7 and 9) and no reliable contribution to the screw dislocations in the zig-zag LABs formed by edge dislocations of the [100](001) and [001](100) systems (Fig. 8).

The creation of a closed (3D) subgrain cell in olivine requires edge and screw dislocations with both [100] and [001] Burger vectors and, hence, it involves activating unfavourable ("hard") slip systems. Two different mechanisms might enable the activation of these slip systems: (1) local stresses may strongly differ in magnitude and/or orientation from the macroscopic one due to grain interactions and (2) the increase of intracrystalline distortion with strain due to the accumulation of LABs might place parts of the grain in positions where another dislocation system is more favourable. Both mechanisms are compatible and can operate simultaneously. Indeed, the EBSD maps show evidence of both. The evidence for the involvement of high local stresses is that DRX grains develop mainly in highly strained (soft-oriented) grains in contact with hard-oriented olivine grains or pyroxenes (Figs. 2, 3b), where the development of higher than average stresses and/or local changes in stress orientation are expected (Ashby, 1970). Likewise, the accumulation of LABs in highly-strained parent (and remnant) grains result in strong intragranular misorientations, leading to changes in the most favourable slip system across the grain volume (cf. Fig. 14 and Figs. 3b, 4,6 ). The development of LABs composed of dislocations of "hard" slip systems closing subgrains and creating new nuclei for DRX at the grain boundaries and triple joints has also been well described in ice Ih (Chauve et al., 2017a).

\subsubsection{From subgrain (LABs) to grain boundaries (HAGBs)}

The misorientation analysis suggests that when LABs evolve into HAGBs they are no longer subjected to the same crystallographic constraints. HAGBs show a large variety of rotations axis that are not observed in LABs (Fig. 10). A few (samples 980A87, VS14-7) show a shift from the typical maximum around [010] in the LABs to $\langle 101\rangle$ in the HAGBs (Fig. 10). Most of them, however, show shifts towards multiple rotation axes that are hard to systematize when comparing among samples or different parts of the same sample, though in many cases, a maximum close to $\langle 101\rangle$ and dispersion of misorientations between [010] and $\langle 110\rangle$ are observed. A marked change in the misorientation axes from related to the active slip systems in the LABs to not related in HAGBs was previously observed in calcite recrystallized by SGR and was interpreted as a result of a change in the dominant deformation accommodation mechanism from the DRX to the grain boundary sliding domain (Bestmann and Prior, 2003). In our samples, however, these changes in misorientation axes occur in HAGB delimiting sub-structured grains, some of them with highly irregular traces (Figs. 10, 15), in HAGB delimiting recrystallized grains within a porphyroclast (Figs. 12, 15), and more generally along the whole recrystallization front (Figs. 10, 15). Such configurations are not consistent with significant grain boundary sliding producing grain rotation, indicating that the cause(s) of this shift in the misorientation axis lies in the transition from LAB to HAGB itself. These observations led us to exclude grain boundary sliding as the process accounting for the abrupt changes in the rotation axis from LABs to HAGBs.

As the misorientation axes observed across the HAGBs cannot be achieved simply by continuously incorporating the edge dislocations proposed to explain the formation and evolution of the LABs, the transition in misorientation axes from the LAB to the HAGBs calls for a change in the structure of the boundaries. This suggests the development of new defects to accommodate the local lattice distortion. Some 
VS14-7
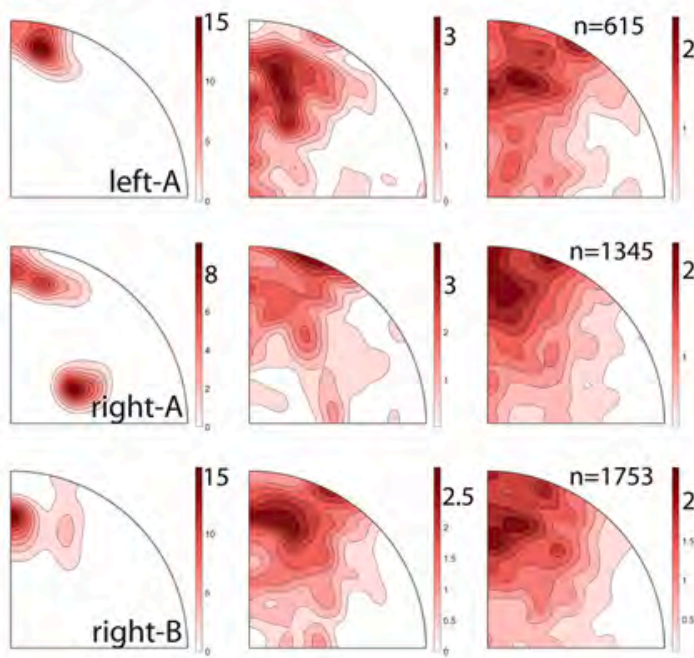

VS14-9
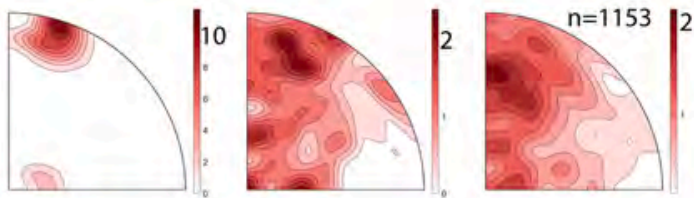

980A87
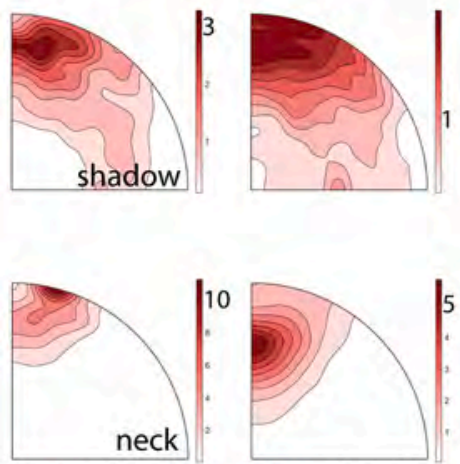

Parent grains
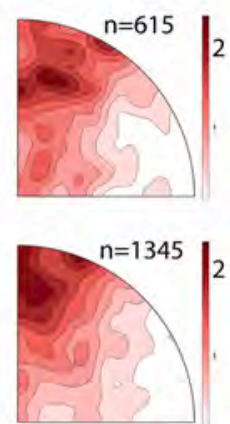

VS15ab-2
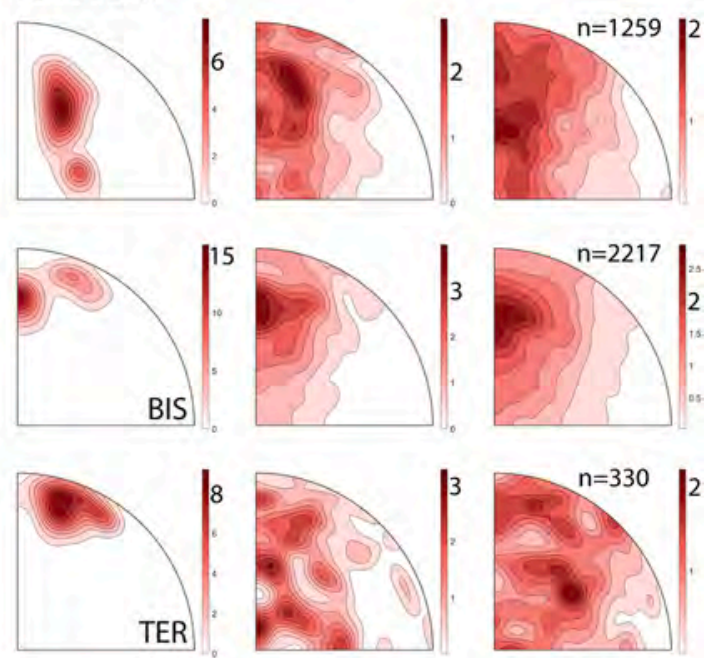

VS15b-1
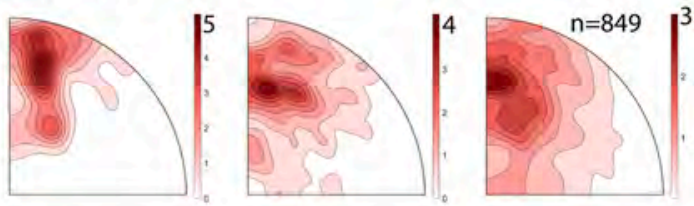

VS15a-1
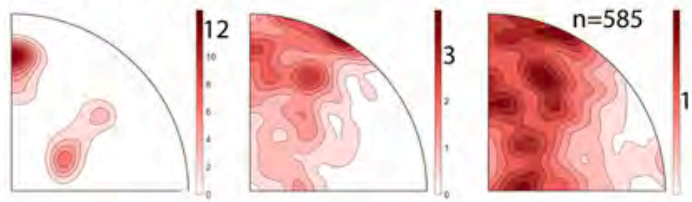

\section{VS5ab-1}
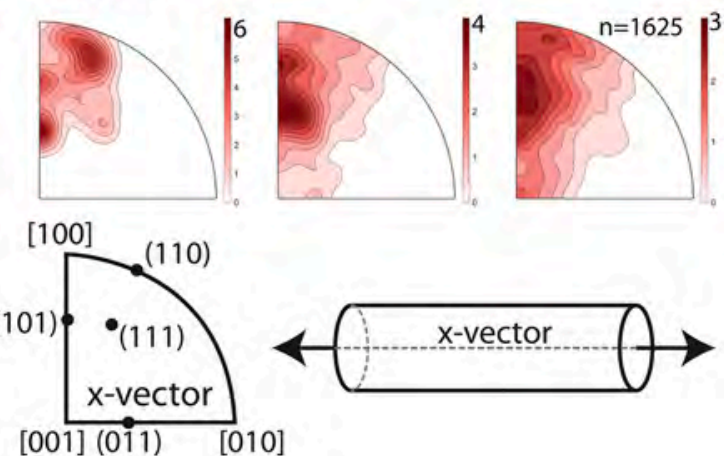

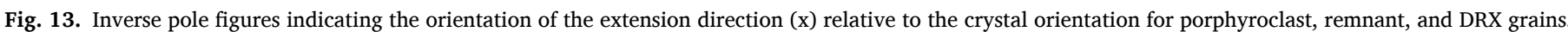

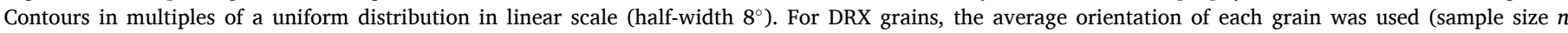
is indicated).

plausible candidates would be new types of dislocations (Fig. 12 points, for instance, for a high proportion of screw dislocations with both [100] and [001] Burger vectors in the HAGBs) or other defects such as disclinations (Cordier et al., 2014) or disconnections (Hirth et al., 2020; Hirth and Pond, 1996). The interaction between the moving dislocations and the new grain boundaries probably contributed to the development of these defects. Deformation experiments combining high-resolution digital image correlation and EBSD in metals (Harte et al., 2020) or ice (Chauve et al., 2017b) have shown evidence for a local increase in lattice distortion (misorientation) on a scale of few micrometres from grain boundaries. Post-mortem studies using high angular resolution EBSD (Guo et al., 2014; Larrouy et al., 2015) and in situ deformation
TEM experiments (Kondo et al., 2016) showed that when there is poor alignment between the slip system of the incoming dislocation and the easy slip systems in the adjacent grain, grain boundaries block the slip transfer either partially or completely, producing dislocation pile-ups and stress concentrations. In situ deformation TEM experiments also showed that dislocations crossing a grain boundary may interact with the dislocations composing the boundary and create segments with different dislocation character and Burger vectors (Kondo et al., 2016). 

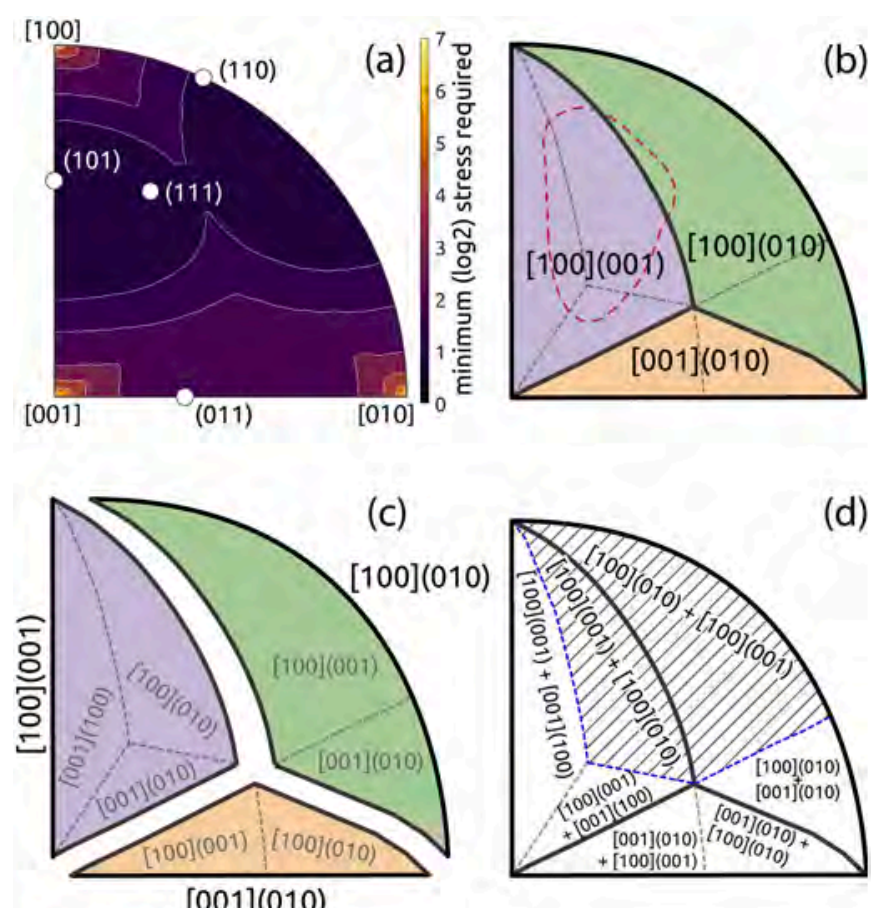

Fig. 14. Inverse pole figure (IPF) maps showing the most favourable slip systems as a function of the orientation of the crystal relative to the extension direction ( $\mathrm{x}$ ) estimated using the critical shear resolved stresses (CRSS) of the four main slip systems of olivine at high-temperature conditions (Tommasi and Vauchez, 2015). (a) Minimum relative stress (normalized by the CRSS of the weakest slip system) required to deform the crystal (base 2 logarithmic scale: olivine crystals with orientations along the different contour lines require twice or half the stress to be deformed by dislocation glide then the adjacent contour). (b, c, d) IPF maps showing the most favourable (weakest) glide system depending on crystal orientation and CRSS (b), the second weaker (c), and the combination of both (d). The dashed field in (d) indicates where [100] glide dominates over [100] + [001]. The pink dashed line in (b) indicates the orientation range above one multiple of a random distribution of the softoriented porphyroclast in Fig. 3. Note that it spreads through several regions with different preferential slip systems. (For interpretation of the references to colour in this figure legend, the reader is referred to the web version of this article.)

\subsection{Changes in crystallographic preferred orientation induced by SGR recrystallization}

Comparison between the olivine CPO in the neck and the shadow zones of sample 980A87 (Fig. 13), which due to the small grain size sample representative volumes, shows that the general $\mathrm{CPO}$ evolution follows the one expected for olivine during axial extension: [100] tends to rotate towards the extension direction, aligning in a small circle around it and [010] tends to align normal to the extension direction. Similar patterns were documented in synthetic dry olivine $\left(\mathrm{Fo}_{50}\right)$ aggregates subjected to axial extension (Hansen et al., 2016). This CPO evolution is consistent with the dominant activity of the [100](010) slip system, typical of high-temperature deformation in olivine under dry conditions.

Comparison between the parent, remnant, and DRX grains CPO in the neck zone (Fig. 13) allows unravelling the effects of deformation and recrystallization. There is an increasing spread in the CPO from parents to remnants to DRX grains, but the most marked variation is between parents and remnant grains. This change is not only in intensity but also in the pattern. Both remnant and DRX grains in the neck zone show alignment of $\langle 101\rangle$ parallel to the extension direction, whereas the parent grains show rather a concentration of [100] axes within 5-20 degrees of the extension direction, a CPO that is closer to that predicted by viscoplastic self-consistent models that consider solely deformation by dislocation glide (cf. Fig. 2 of Knoll et al., 2009). Thus remnant and DRX grains are in softer orientations than the parent grains (cf. stress IPF in Fig. 3b). These observations highlight two consequences of SGR recrystallization on the $\mathrm{CPO}$ evolution: it promotes dispersion from the characteristic maxima produced by dislocation glide and favours the development of soft orientations. Viscoplastic self-consistent simulations (VPSC) performed in the companion article (Ben Ismail et al., 2021) support that this CPO evolution tends to weaken the sample.

Analysis of the intragranular misorientations in highly strained parent grains shows that the addition of different LABs may produce major cumulative orientation gradients (up to 80 degrees to the reference orientation in a few tens of microns, see profiles in Figs. 4c, 6c). Dominant rotations around [010] and secondarily around [001] associated with these LABs (Fig. 10) explain a large part of the observed changes in the CPO between parent and remnant or DRX grains, but not all (Fig. 13). The latter may however be explained by the additional rotation axes documented across HAGBs (Fig. 10).

Previous studies have invoked activation of grain boundary sliding to account for the dispersion of the CPO in recrystallized domains relative to the orientations of the parent grains (e.g. Bestmann and Prior, 2003). However, as discussed in Section 4.2.1, our observations indicate that SGR recrystallization produces by itself an intense dispersion of the CPO and thus this phenomenon cannot be used as irrefutable proof of the activation of grain boundary sliding when SGR recrystallization occurs. A similar conclusion, but based on less stringent observational constraints, had already been proposed based on the analysis of variably recrystallized natural peridotites (Falus et al., 2011). The similar evolution in CPO between the parent, remnant, and DRX grains in the shadow zone of sample 980A87, which preserves the mylonitic microstructure formed in a natural shear zone, supports that the same processes are active under natural conditions (Fig. 13). The difference in CPO between the shadow and neck zone may be explained by different deformation regimes: simple shear in nature and axial extension in the experiments.

\section{Conclusions}

We document how dynamic recrystallization by subgrain rotation (SGR-DRX) develops in olivine using high-resolution electron backscatter diffraction (EBSD) mapping in natural peridotites deformed in extension at high temperature $\left(1200{ }^{\circ} \mathrm{C}\right)$ up to $50 \%$ bulk finite strain. These data provide evidence for:

1. SGR-DRX occurs preferentially in highly-strained grains in contact with harder ones, where local stress concentrations and higher GND densities develop.

2. SGR-DRX in olivine is characterized by the development of tilt LABs, which are essentially composed of edge dislocations of the [100] (001), [001](100), [100](010) and [001](010) systems, in order of decreasing frequency. They are characterized by misorientations around [010] (the dominant rotation axis), [001], $\langle 0 \mathrm{vw}\rangle$, and, less frequently [100]. Analysis of the traces of these tilt LABs suggests that they have $\{h 0 l\}$ planes. The twist LABs parallel to (010) composed by [100] and [001] screw dislocations observed by TEM could not be reliably detected due to the 2D nature of the EBSD data.

3. The activation of these dislocation systems agrees with a Schmid factor analysis using values for high-temperature deformation in olivine, but the latter does not explain the relative frequency of the different dislocation types within the LABs. This discrepancy indicates that a crystal well-oriented for slip along [100](010) might accommodate most of the imposed deformation through unimpeded glide of [100](010) dislocations across the crystal without generating LABs, unless its deformation is locally impeded by harder neighboring grains. 
STEP 1. Formation of subgrain cells and dislocation types controlling the geometry and misorientation of $\angle A B S<15^{\circ}$
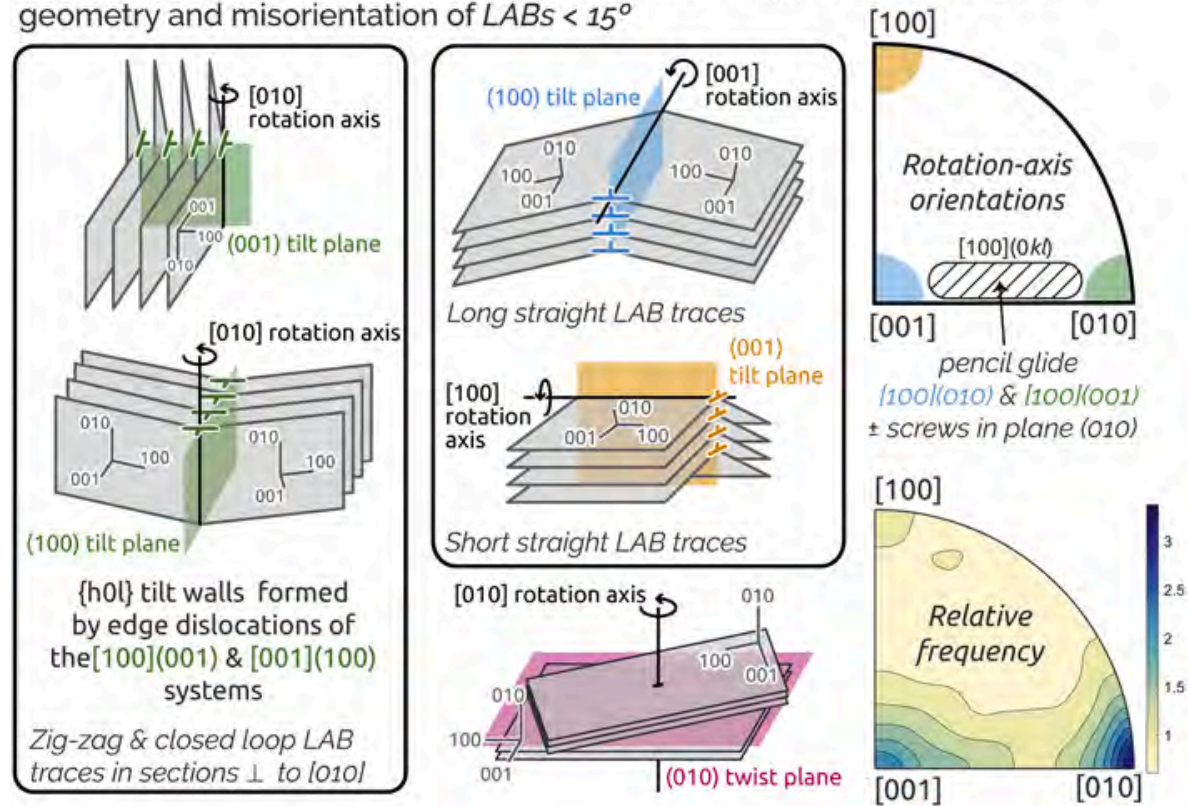

STEP 2. Transition to high-angle grain boundaries (HAGBs $>15^{\circ}$ )
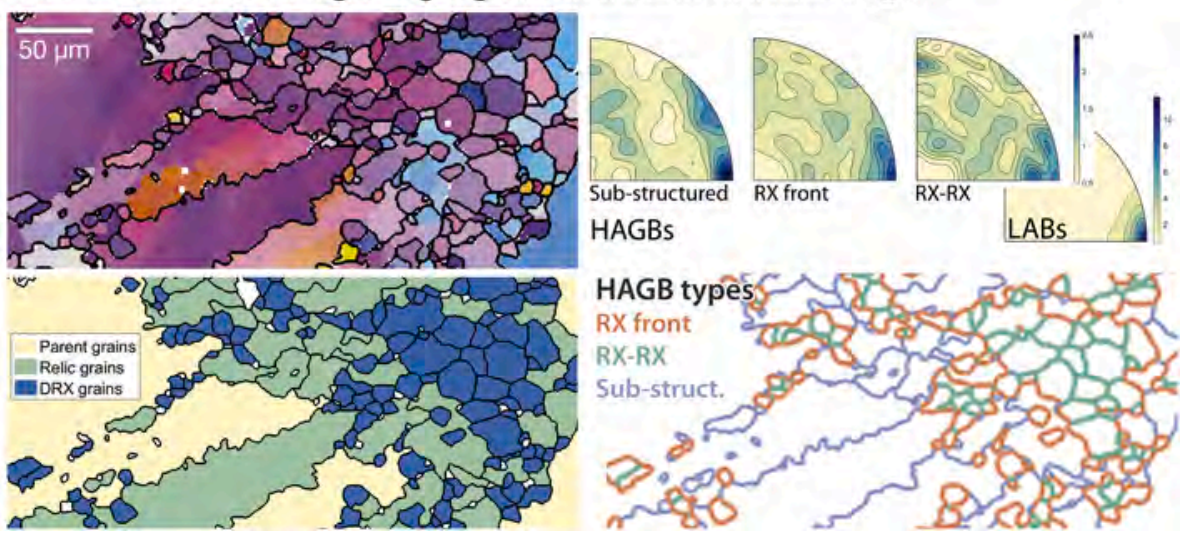

Fig. 15. Synoptic scheme showing the evolution and main features of the boundaries leading to dynamic recrystallization by subgrain rotation in olivine.

4. The formation of 3D closed subgrain cells needed for the generation of recrystallized grains by SGR requires the contribution of at least three different slip systems. It inevitably involves the activation of hard slip systems in olivine and requires high (local) stresses.

5. There is a sharp change in the misorientation axes across HAGBs relatively to those observed in LABs. We suggest that this change marks the development and incorporation of new types of defects at or nearby the HAGBs due to the interaction of dislocations and grain boundaries characterized by a strong misalignment between the slip systems in the neighbouring grain pairs.

6. Analysis of the cumulative intragranular misorientations in highly strained parent grains and the evolution of the CPO between the parent and the DRX grains shows that SGR-DRX results in intense dispersion of the CPO. Consequently, observation of CPO dispersion in DRX domains cannot be used as certain evidence for the activation of grain boundary sliding.

7. This study further demonstrates the potential of the SEM-EBSD technique to study dislocation substructures in LABs and HAGBs. Compared to TEM, this method enables collecting data over large areas and establishing robust statistics.

\section{Data availability}

Datasets related to this article can be found at https://doi.org/10 $.17632 / 8 \mathrm{dm} 87 \mathrm{k} 7 \mathrm{~cm} 8.1$

\section{Declaration of Competing Interest}

The authors declare that they have no known competing financial interests or personal relationships that could have appeared to influence the work reported in this paper.

\section{Acknowledgements}

We dedicate this article to A. Nicolas, an exceptional researcher who set the basis of the petrophysical analysis of mantle deformation. The experiments were carried out with support from an EU-Marie Skłodowska-Curie postdoctoral fellowship to WBI. The EBSD data analysis was supported by a postdoctoral fellowship co-funded by the European Union and the Government of the Principality of Asturias (Spain) [grant number ACA17-32] within the Marie Skłodowska-Curie COFUND Actions FP7 to MALS and by the European Research Council (ERC) under the European Union's Horizon 2020 Research and Innovation programme (grant agreement No 882450 - ERC RhEoVOLUTION). 
Françoise Boudier and Adolphe Nicolas are thanked for the providing the Oman sample and David Mainprice for helpful discussions. We thank the reviews by Geoffrey E. Lloyd and an anonymous reviewer and the editorial guidance of Philippe Agard.

\section{References}

Ashby, M.F., 1970. The deformation of plastically non-homogeneous materials. Philos. Mag. 21 https://doi.org/10.1080/14786437008238426.

Bachmann, F., Hielscher, R., Schaeben, H., 2010. Texture Analysis with MTEX - Free and Open Source Software Toolbox. Solid State Phenom. 160, 63-68. https://doi.org/ 10.4028/www.scientific.net/SSP.160.63.

Bai, Q., Kohlstedt, D.L., 1992. High-temperature creep of olivine single crystals, 2. Dislocation structures. Tectonophysics 206, 1-29. https://doi.org/10.1016/00401951(92)90365-D.

Bai, Q., Mackwell, S.J., Kohlstedt, D.L., 1991. High-temperature creep of olivine single crystals: 1. Mechanical results for buffered samples. J. Geophys. Res. 96 https://doi. org/10.1029/90JB01723.

Ben Ismail, W., Tommasi, A., Lopez-Sanchez, M.A., Barou, F., Rutter, E.H., 2021. Deformation of upper mantle rocks with contrasting initial fabrics in axial extension. Tectonophysics (this volume, preprint at arXiv:2101.03362).

Bergmann, R., Chan, R.H., Hielscher, R., Persch, J., Steidl, G., 2016. Restoration of manifold-valued images by half-quadratic minimization. Inverse Probl. Imaging 10. https://doi.org/10.3934/ipi.2016001.

Bestmann, M., Prior, D.J., 2003. Intragranular dynamic recrystallization in naturally deformed calcite marble: diffusion accommodated grain boundary sliding as a result of subgrain rotation recrystallization. J. Struct. Geol. 25, 1597-1613. https://doi. org/10.1016/S0191-8141(03)00006-3.

Bilby, B.A., Gardner, L.R.T., Smith, E., 1958. The relation between dislocation density and stress. Acta Metall. 6 https://doi.org/10.1016/0001-6160(58)90088-9.

Chauve, T., Montagnat, M., Barou, F., Hidas, K., Tommasi, A., Mainprice, D., 2017a. Investigation of nucleation processes during dynamic recrystallization of ice using cryo-EBSD. Philos. Trans. A. Math. Phys. Eng. Sci. 375, 20150345. https://doi.org/ 10.1098/rsta.2015.0345.

Chauve, T., Montagnat, M., Lachaud, C., Georges, D., Vacher, P., 2017b. Strain field evolution at the ductile-to-brittle transition: a case study on ice. Solid Earth 8, 943-953. https://doi.org/10.5194/se-8-943-2017.

Cordier, P., Demouchy, S., Beausir, B., Taupin, V., Barou, F., Fressengeas, C., 2014. Disclinations provide the missing mechanism for deforming olivine-rich rocks in the mantle. Nature 507, 51-56. https://doi.org/10.1038/nature13043.

Darot, M., Gueguen, Y., 1981. High- temperature creep of forsterite single crystals. J. Geophys. Res. 86 https://doi.org/10.1029/jb086ib07p06219.

De Kloe, R., 2001. Deformation Mechanisms and Melt Nano-Structures in Experimentally Deformed Olivine-Orthopyroxene Rocks with Low Melt Fractions. Thesis. http://dsp ace.library.uu.nl/handle/1874/528.

Doherty, R.D., Hughes, D.A., Humphreys, F.J., Jonas, J.J., Juul Jensen, D., Kassner, M.E., King, W.E., McNelley, T.R., McQueen, H.J., Rollett, A.D., 1997. Current issues in recrystallization: a review. Mater. Sci. Eng. 238, 219-274. https://doi.org/10.1016/ S1369-7021(98)80046-1.

Drury, M.R., Pennock, G.M., 2007. Subgrain rotation recrystallization in minerals. Mater. Sci. Forum 550, 95-104. https://doi.org/10.4028/0-87849-434-0.95.

Durham, W.B., Goetze, C., Blake, B., 1977. Plastic flow of oriented single crystals of olivine: 2. Observations and interpretations of the dislocation structures. J. Geophys. Res. 82, 5755-5770. https://doi.org/10.1029/JB082i036p05755.

Falus, G., Tommasi, A., Soustelle, V., 2011. The effect of dynamic recrystallization on olivine crystal preferred orientations in mantle xenoliths deformed under varied stress conditions. J. Struct. Geol. 33 https://doi.org/10.1016/j.jsg.2011.09.010.

Gao, H., Huang, Y., 2003. Geometrically necessary dislocation and size-dependent plasticity. Scr. Mater. 48, 113-118. https://doi.org/10.1016/S1359-6462(02) 00329-9.

Goetze, C., Kohlstedt, D.L., 1973. Laboratory study of dislocation climb and diffusion in olivine. J. Geophys. Res. 78, 5961-5971. https://doi.org/10.1029/ jb078i026p05961.

Gueguen, Y., 1979. High temperature olivine creep: evidence for control by edge dislocations. Geophys. Res. Lett. 6 https://doi.org/10.1029/GL006i005p00357.

Guillope, M., Poirier, J., 1979. Dynamic recrystallization during creep of singlecrystalline halite: an experimental study. J. Geophys. Res. Solid Earth 84, 5557. https://doi.org/10.1029/JB084iB10p05557.

Guo, Y., Britton, T.B., Wilkinson, A.J., 2014. Slip band-grain boundary interactions in commercial-purity titanium. Acta Mater. 76 https://doi.org/10.1016/j. actamat.2014.05.015.

Guo, Y., Collins, D.M., Tarleton, E., Hofmann, F., Wilkinson, A.J., Britton, T. Ben, 2020. Dislocation density distribution at slip band-grain boundary intersections. Acta Mater. 182, 172-183. https://doi.org/10.1016/j.actamat.2019.10.031.

Hansen, L.N., Warren, J.M., Zimmerman, M.E., Kohlstedt, D.L., 2016. Viscous anisotropy of textured olivine aggregates, part 1: Measurement of the magnitude and evolution of anisotropy. Earth Planet. Sci. Lett. 445, 92-103. https://doi.org/10.1016/j. eps1.2016.04.008.

Harte, A., Atkinson, M., Preuss, M., da Fonseca, J.Q., 2020. A statistical study of the relationship between plastic strain and lattice misorientation on the surface of a deformed Ni-based superalloy. Acta Mater. 195, 555-570. https://doi.org/10.1016/ j.actamat.2020.05.029.
Hielscher, R., Silbermann, C.B., Schmidla, E., Ihlemannb, J., 2019. Denoising of crystal orientation maps. J. Appl. Crystallogr. 52, 984-996. https://doi.org/10.1107/ S1600576719009075.

Hirth, J.P., Pond, R.C., 1996. Steps, dislocations and disconnections as interface defects relating to structure and phase transformations. Acta Mater. 44 https://doi.org/ 10.1016/S1359-6454(96)00132-2.

Hirth, J.P., Hirth, G., Wang, J., 2020. Disclinations and disconnections in minerals and metals. Proc. Natl. Acad. Sci. U. S. A. 117, 196-204. https://doi.org/10.1073/ pnas.1915140117.

Huang, K., Logé, R., 2016. A review of dynamic recrystallization phenomena in metallic materials. Mater. Des. 111, 548-574. https://doi.org/10.1016/J. MATDES.2016.09.012.

Ion, S.E., Humphreys, F.J., White, S.H., 1982. Dynamic recrystallisation and the development of microstructure during the high temperature deformation of magnesium. Acta Metall. 30, 1909-1919. https://doi.org/10.1016/0001-6160(82) 90031-1.

Jaoul, O., Michaut, M., Gueguen, Y., Ricoult, D., 1979. Decorated dislocations in forsterite. Phys. Chem. Miner. 5, 15-19. https://doi.org/10.1007/BF00308165.

Kirby, S.H., Wegner, M.W., 1978. Dislocation substructure of mantle-derived olivine as revealed by selective chemical etching and transmission electron microscopy. Phys. Chem. Miner. 3, 309-330. https://doi.org/10.1007/BF00311845.

Knoll, M., Tommasi, A., Logé, R.E., Signorelli, J.W., 2009. A multiscale approach to model the anisotropic deformation of lithospheric plates. Geochem. Geophys. Geosyst. 10 https://doi.org/10.1029/2009GC002423.

Kondo, S., Mitsuma, T., Shibata, N., Ikuhara, Y., 2016. Direct observation of individual dislocation interaction processes with grain boundaries. Sci. Adv. 2, e1501926 https://doi.org/10.1126/sciadv.1501926.

Kröner, E., 1958. Continuum theory of dislocations and self-stresses. Ergebnisse der Angew. Math. 5.

Larrouy, B., Villechaise, P., Cormier, J., Berteaux, O., 2015. Grain boundary-slip bands interactions: impact on the fatigue crack initiation in a polycrystalline forged $\mathrm{Ni}$ based superalloy. Acta Mater. 99 https://doi.org/10.1016/j.actamat.2015.08.009.

Lloyd, G.E., Farmer, A.B., Mainprice, D., 1997. Misorientation analysis and the formation and orientation of subgrain and grain boundaries. Tectonophysics 279 . https://doi. org/10.1016/S0040-1951(97)00115-7.

Lopez-Sanchez, M.A., Tommasi, A., Barou, F., Quey, R., 2020. Dislocation-driven recrystallization in AZ31B magnesium alloy imaged by quasi-in situ EBSD in annealing experiments. Mater. Charact. 165, 110382. https://doi.org/10.1016/j. matchar.2020.110382.

Mainprice, D., Lloyd, G.E., Casey, M., 1993. Individual orientation measurements in quartz polycrystals: advantages and limitations for texture and petrophysical property determinations. J. Struct. Geol. 15 https://doi.org/10.1016/0191-8141 (93)90162-4.

Mainprice, D., Bachmann, F., Hielscher, R., Schaeben, H., 2014. Descriptive tools for the analysis of texture projects with large datasets using MTEX: strength, symmetry and components. Geol. Soc. Lond. Spec. Publ. 409, 251-271. https://doi.org/10.1144/ SP409.8.

Mussi, A., Cordier, P., Demouchy, S., Hue, B., 2017. Hardening mechanisms in olivine single crystal deformed at $1090^{\circ} \mathrm{C}$ : an electron tomography study. Philos. Mag. 97, 3172-3185. https://doi.org/10.1080/14786435.2017.1367858.

Nye, J.F., 1953. Some geometrical relations in dislocated crystals. Acta Metall. 1 https:// doi.org/10.1016/0001-6160(53)90054-6.

Pantleon, W., 2008. Resolving the geometrically necessary dislocation content by conventional electron backscattering diffraction. Scr. Mater. 58 https://doi.org/ 10.1016/j.scriptamat.2008.01.050.

Phakey, P., Dollinger, G., Christie, J., 1972. Transmission Electron Microscopy of Experimentally Deformed Olivine Crystals, pp. 117-138, 10.1029/GM016p0117.

Poirier, J., Guillope, M., 1979. Deformation induced recrystallization of minerals. Bull. Mineral. 102, 67-74.

Poirier, J., Nicolas, A., 1975. Deformation-induced recrystallization due to progressive misorientation of subgrains, with special reference to mantle peridotites. J. Geol. 83, 707-720.

Prior, D.J., Boyle, A.P., Brenker, F., Cheadle, M.C., Day, A., Lopez, G., Peruzzo, L., Potts, G.J., Reddy, S., Spiess, R., Timms, N.E., Trimby, P.W., Wheeler, J., Zetterström, L., 1999. The application of electron backscatter diffraction and orientation contrast imaging in the SEM to textural problems in rocks. Am. Mineral. 84, 1741-1759.

Randle, V., Ralph, B., 1986. A practical approach to the determination of the crystallography of grain boundaries. J. Mater. Sci. 21 https://doi.org/10.1007/ BF02431617.

Ricoult, D.L., Kohlstedt, D.L., 1983. Structural width of low-angle grain boundaries in olivine. Phys. Chem. Miner. 9 https://doi.org/10.1007/BF00308370.

Sakai, T., Belyakov, A., Kaibyshev, R., Miura, H., Jonas, J.J., 2014. Dynamic and postdynamic recrystallization under hot, cold and severe plastic deformation conditions. Prog. Mater. Sci. 60, 130-207. https://doi.org/10.1016/J.PMATSCI.2013.09.002.

Seret, A., Moussa, C., Bernacki, M., Signorelli, J., Bozzolo, N., 2019. Estimation of geometrically necessary dislocation density from filtered EBSD data by a local linear adaptation of smoothing splines. J. Appl. Crystallogr. 52 https://doi.org/10.1107/ S1600576719004035.

Soustelle, V., Tommasi, A., Demouchy, S., Ionov, D.A., 2010. Deformation and fluid-rock interaction in the supra-subduction mantle: microstructures and water contents in peridotite xenoliths from the Avacha volcano, Kamchatka. J. Petrol. 51 https://doi. org/10.1093/petrology/egp085.

Tommasi, A., Vauchez, A., 2015. Heterogeneity and anisotropy in the lithospheric mantle. Tectonophysics 661, 11-37. https://doi.org/10.1016/j.tecto.2015.07.026. 
Urai, J.L., Means, W.D., Lister, G.S., 1986. Dynamic recrystallization of minerals. In: Heard, H., Hobbs, B. (Eds.), Mineral and Rock Deformation: Laboratory Studies; the Paterson Volume. AGU Geophysical Monograph 36, Washington DC, pp. 161-199. https://doi.org/10.1029/GM036.
Wheeler, J., Prior, D.J., Jiang, Z., Spiess, R., Trimby, P.W., 2001. The petrological significance of misorientations between grains. Contrib. Mineral. Petrol. 141, 109 124. https://doi.org/10.1007/s004100000225.

Wilkinson, A.J., 2001. A new method for determining small misorientations from electron back scatter diffraction patterns. Scr. Mater. 44 https://doi.org/10.1016 S1359-6462(01)00943-5. 